\title{
Variability and Accuracy of Target Displacement from Nonlinear Static Procedures
}

\author{
Rakesh K. Goel \\ Department of Civil and Environmental Engineering, California Polytechnic State University, San Luis Obispo, CA 93407-0353, USA \\ Correspondence should be addressed to Rakesh K. Goel, rgoel@calpoly.edu
}

Received 13 December 2010; Accepted 19 January 2011

Academic Editors: R. Jangid, S. Pantazopoulou, and I. Takewaki

Copyright ( $) 2011$ Rakesh K. Goel. This is an open access article distributed under the Creative Commons Attribution License, which permits unrestricted use, distribution, and reproduction in any medium, provided the original work is properly cited.

This paper compares the target displacement estimate from four current nonlinear static procedures-FEMA-356 CM, ASCE41 CM, ATC-40 CSM, and FEMA-440 CSM-with the value derived from recorded motions of five strongly shaken reinforced concrete buildings. This comparison provides useful insight into two important questions: (1) how much does the target displacement vary among the four nonlinear static procedures? and (2) can the engineering profession "accurately" predict the response of a real building during an earthquake event using currently available modeling techniques and pushover analysis procedures? It is shown that these procedures may lead to significantly different estimates of the target displacement, particularly for short-period buildings responding in the nonlinear range. Furthermore, various nonlinear static procedures applied to nonlinear models developed using generally accepted engineering practice provide either significant over estimation or under estimation of the target roof displacement when compared to the value derived from recorded motions.

\section{Introduction}

Nonlinear static procedure (NSP) or pushover analysis is widely used for seismic design/evaluation of buildings. The NSP requires nonlinear static pushover analysis of the structure subjected to monotonically increasing lateral forces with specified height-wise distribution until a target displacement is reached. The building design is deemed to be acceptable if seismic demands (e.g., plastic hinge rotations, drifts, etc.) at the target displacement are within acceptable values.

The two widely used procedures to estimate the target displacement in the NSP are: (1) the Coefficient Method (CM) defined in the FEMA-356 document [1], and (2) the Capacity Spectrum Method (CSM) specified in the ATC-40 document [2]. The CM utilizes a displacement modification procedure in which the target displacement is computed by modifying displacement of a linearly-elastic, single-degree-of-freedom (SDF) system by several empirical coefficients. The SDF system has the same period and damping as the fundamental mode of the original building. The CSM is a form of equivalent linearization in which the target displacement is estimated by multiplying elastic displacement of an SDF system by the fundamental mode participation factor. The SDF system has larger (effective) period and damping than the original building. The CSM uses empirical relationships for the effective period and damping as a function of ductility to estimate displacement of an equivalent linear SDF system.

Most previous investigations on development and evaluation of the CM and/or CSM to compute the target displacement used computer models of buildings; an exhaustive list of references is available in the FEMA-440 report [3]. These investigations primarily focused on the "accuracy" of various nonlinear static procedures in predicting target displacement of computer models; the "exact" value of the target roof displacement was taken as the peak roof displacement computed by nonlinear response history analysis of the computer model subjected to selected earthquake motion at its base. Because the "exact" target displacement and the value from various nonlinear static procedures used the same computer model, these investigations eliminated the discrepancy due to modeling assumptions; errors examined were only due to nonlinear static procedures. Recent investigations on this topic found significant variability in the target displacements from various procedures $[4,5]$. 
Recorded motions of strongly shaken buildings, especially those deformed into the nonlinear range, provide a unique opportunity to gain insight into two important questions: (1) how much does the target displacement varies among various nonlinear static procedures? and (2) can the engineering profession "accurately" predict the response of a real building during an earthquake event using currently available modeling techniques and pushover analysis procedures? While past studies that used either generic or well-calibrated computer models have provided significant insight into the first question, the additional data generated in this investigation using validated computer models of real buildings is useful in either confirming or contradicting the previous findings. The insight into the second question can only be gained by comparing the roof displacement estimated from various nonlinear static procedures applied to a computer model, developed using generally accepted engineering practice, of the building with the value observed during an actual earthquake event. This investigation is specifically aimed at filling this need.

The procedures considered in this investigation are: (1) CM defined in the FEMA-356 document [1], (2) improved CM proposed in the FEMA-440 report [3] and adopted in the ASCE-41 standard [6], (3) CSM defined in the ATC-40 document [2], and (4) improved CSM proposed by Guyader and Iwan [7] and adopted in the FEMA-440 report [3].

\section{Selected Buildings}

Recorded motions of buildings that were strongly shaken and potentially deformed beyond the yield limit during the earthquake are required for this investigation. For this purpose, five concrete buildings, ranging from low-rise to high-rise, have been selected (Table 1). The strong-motion data used in this investigation are identified in Table 1 for each building. The data selected in this investigation are the processed data available from the Center for Engineering Strong Motion Data (CESMD) (http://www.strongmotioncenter.org). The data processing procedure involves low-pass and high-pass filtering using Ormsby filters. Further details of the data processing are available in a paper by Shakal et al. [8].

The distance from building to epicenter of the earthquake (Table 1) indicates that the selected buildings were most likely subjected to near-fault motions. Although results are not presented here for brevity's sake, response spectra for motions recorded at the base of several of these buildings indicated characteristics compatible with those expected for near-fault motions; a more comprehensive discussion on how to identify near-fault effects from response spectra is available in Chopra [9].

\section{Procedures to Compute Target Displacement}

3.1. FEMA-356 Coefficient Method. The target displacement in the FEMA-356 CM [1] is computed from

$$
\delta_{t}=C_{0} C_{1} C_{2} C_{3} S_{a} \frac{T_{e}^{2}}{4 \pi^{2}} g
$$

where $S_{a}=$ response spectrum acceleration at the effective fundamental vibration period and damping ratio of the building under consideration, $g=$ acceleration due to gravity; $T_{e}=$ effective fundamental period of the building in the direction under consideration computed by modifying the fundamental vibration period from elastic dynamic analysis, for example, eigen-value analysis, $T_{i}$, by

$$
T_{e}=T_{i} \sqrt{\frac{K_{i}}{K_{e}}}
$$

in which $K_{i}$ is the elastic stiffness of the building and $K_{e}$ is the effective stiffness of the building obtained by idealizing the pushover curve as a bilinear relationship; $C_{0}=$ coefficient to relate the elastic response of an SDF system to the elastic displacement of the multi-degree-offreedom (MDF) building at the control node taken as the first mode participation factor or selected from tabulated values in the FEMA-356 document $C_{1}=$ coefficient to relate the maximum inelastic and elastic displacement of the SDF system computed from

$$
C_{1}= \begin{cases}1.0 ; & T_{e} \geq T_{s}, \\ \frac{1.0+(R-1) T_{s} / T_{e}}{R} ; & T_{e}<T_{s}, \\ 1.5 ; & T_{e}<0.1 \mathrm{~s}\end{cases}
$$

in which $R$ is the ratio of elastic and yield strengths and $T_{s}$ is the corner period where the response spectrum transitions from constant pseudoacceleration to constant pseudovelocity. $C_{2}=$ coefficient to represent the effects of pinched hysteretic shape, stiffness degradation, and strength deterioration selected either from tabulated values depending on the framing system (see FEMA-356 for details of various framing systems) and the performance level or taken as one for nonlinear analysis, and $C_{3}=$ coefficient to represent increased displacement due to $P-\Delta$ effects computed from

$$
C_{3}= \begin{cases}1.0 ; & \alpha \geq 0, \\ 1.0+\frac{|\alpha|(R-1)^{3 / 2}}{T_{e}} ; & \alpha<0\end{cases}
$$

in which $\alpha$ is the ratio of the postyield stiffness to effective elastic stiffness. In (3) and (4), $R$ is defined as

$$
R=\frac{S_{a}}{V_{y} / W} C_{m}
$$

where $V_{y}$ is the yield strength of the building estimated from pushover curve of the building, $W$ is the effective seismic weight, and $C_{m}$ is the effective modal mass factor for the fundamental mode of the building.

If the FEMA-356 CM were implemented using the seismic hazard defined according to the FEMA-356 provisions, the period $T_{s}$ needed for computation of $C_{1}$ is easily determined from the design response spectrum compatible with the selected seismic hazard. In this investigation, however, the FEMA-356 CM is implemented with seismic hazard defined by the linearly-elastic response spectrum of 
TABLE 1: Five reinforced concrete buildings selected.

\begin{tabular}{lcccc}
\hline Buildings name & CSMIP Station & Stories/basement & Earthquake & Epic. Dist. $(\mathrm{km})$ \\
\hline Imperial County Services Building & 01260 & $6 / 0$ & 1979 Imperial Valley & 28.4 \\
Sherman Oaks Commercial Bldg & 24322 & $13 / 2$ & 1994 Northridge & 9 \\
North Hollywood Hotel & 24464 & $20 / 1$ & 1994 Northridge & 19 \\
Watsonville Commercial Bldg & 47459 & $4 / 0$ & 1989 Loma Prieta & 18 \\
Santa Barbara Office Bldg & 25213 & $3 / 0$ & 1978 Santa Barbara & 13 \\
\hline
\end{tabular}

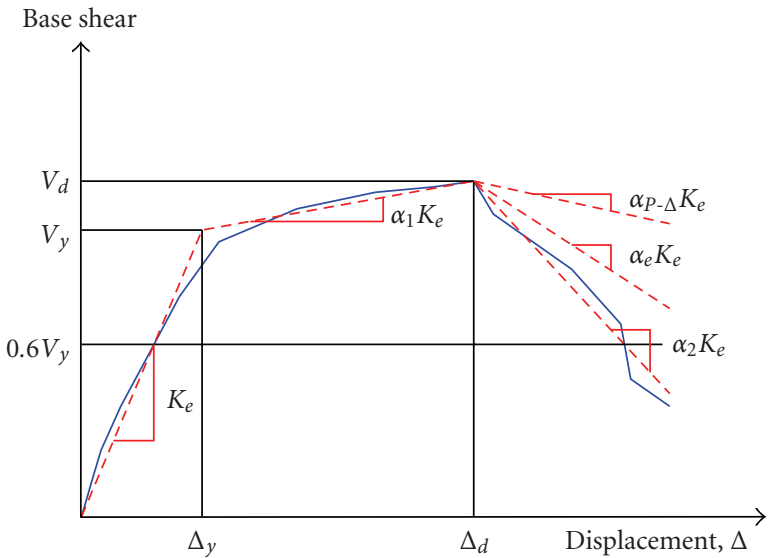

FIgURE 1: Idealized force-deformation curve in ASCE-41 CM.

the motions recorded at the base of the building. Therefore, the period $T_{s}$ was estimated from the linearly-elastic response spectrum of the motion recorded at the base of the building. For this purpose, a smooth spectrum was fitted to the combined D-V-A response spectrum and the period at the intersection of the acceleration-sensitive and velocitysensitive regions was selected to be the period $T_{s}$. Further details of this procedure may be found in Chopra [9].

3.2. ASCE-41 Coefficient Method. The target displacement in the ASCE-41 CM [6] is computed from

$$
\delta_{t}=C_{0} C_{1} C_{2} S_{a} \frac{T_{e}^{2}}{4 \pi^{2}} g
$$

where coefficient $C_{0}$ relates the elastic response of an SDF system to the elastic displacement of the MDF building at the control node taken as the first mode participation factor. The coefficient $C_{1}$ is given by

$$
C_{1}= \begin{cases}1.0 ; & T_{e}>1.0 \mathrm{~s}, \\ 1.0+\frac{R-1}{a T_{e}^{2}} ; & 0.2 \mathrm{~s}<T_{e} \leq 1.0 \mathrm{~s}, \\ 1.0+\frac{R-1}{0.04 a} ; & T_{e} \leq 0.2 \mathrm{~s}\end{cases}
$$

in which $a$ is equal to 130 for soil site class A and B, 90 for soil site class C, and 60 for soil site classes D, E, and F (see
ASCE-41 for details of various site classes), respectively. The coefficient $C_{2}$ is given by

$$
C_{2}= \begin{cases}1.0 ; & T_{e}>0.7 \mathrm{~s} \\ 1+\frac{1}{800}\left(\frac{R-1}{T_{e}}\right)^{2} ; & T_{e} \leq 0.7 \mathrm{~s}\end{cases}
$$

Finally, the ASCE-41CM imposes limitation on $R$ to avoid dynamic instability as

$$
R \leq R_{\max }=\frac{\Delta_{d}}{\Delta_{y}}+\frac{\left|\alpha_{e}\right|^{-h}}{4} ; \quad h=1.0+0.15 \ln \left(T_{e}\right)
$$

in which $\Delta_{d}$ is the deformation corresponding to peak strength, $\Delta_{y}$ is the yield deformation, and $\alpha_{e}$ is the effective negative postyield slope given by

$$
\alpha_{e}=\alpha_{P-\Delta}+\lambda\left(\alpha_{2}-\alpha_{P-\Delta}\right),
$$

where $\alpha_{2}$ is the negative postyield slope ratio defined in Figure $1, \alpha_{P-\Delta}$ is the negative slope ratio caused by $P-\Delta$ effects, and $\lambda$ is the near-field effect factor given as 0.8 for $S_{1} \geq 0.6$ and 0.2 for $S_{1}<0.6\left(S_{1}\right.$ is defined as the 1-second spectral acceleration for the Maximum Considered Earthquake). The $\alpha_{2}$ slope includes $P-\Delta$ effects, in-cycle degradation, and cyclic degradation.

3.3. ATC-40 Capacity Spectrum Method. The target displacement in the ATC-40 CSM [2] is computed from

$$
\delta_{t}=C_{0} S_{d}\left(T_{\mathrm{eq}}, \zeta_{\mathrm{eq}}\right),
$$

where coefficient $C_{0}$ is the fundamental mode participation factor, and $S_{d}\left(T_{\mathrm{eq}}, \zeta_{\mathrm{eq}}\right)$ is the maximum displacement of a linearly-elastic SDF system with equivalent period, $T_{\mathrm{eq}}$, and equivalent damping ratio, $\zeta_{\text {eq }}$ given by

$$
T_{\mathrm{eq}}=T_{o} \sqrt{\frac{\mu}{1+\alpha \mu-\alpha}} ; \quad \zeta_{\mathrm{eq}}=\zeta_{o}+\kappa \frac{1}{\pi} \frac{(\mu-1)(1-\alpha)}{\mu(1+\alpha \mu-\alpha)}
$$

in which $T_{o}$ is the initial period of vibration of the system, $\alpha$ is the postyield stiffness ratio, $\mu$ is the maximum displacement ductility ratio, and $\kappa$ is the adjustment factor to approximately account for changes in hysteretic behavior of reinforced concrete structure. The ATC-40 document defines three types of hysteretic behaviors-Type A with stable, reasonably full hysteretic loops; Type $\mathrm{C}$ with severely pinched 
and/or degraded loops; and Type B between Types A and Cand provides equations for computing $\kappa$ for each of the three types of hysteretic behavior.

Since the equivalent linearization procedure requires prior knowledge of the displacement ductility ratio (12), ATC-40 document describes three iterative procedures: Procedures A, B, and C. Procedures A and B are the most transparent and convenient for programming, whereas Procedure $\mathrm{C}$ is purely a graphical method. Details of these procedures are available in the ATC- 40 document and are not presented here for brevity's sake.

3.4. FEMA-440 Capacity Spectrum Method. The target displacement in the FEMA-440 CSM [3] is computed from

$$
\delta_{t}=C_{0} S_{d}\left(T_{\text {eff }}, \zeta_{\text {eff }}\right),
$$

where coefficient $C_{0}$ is the fundamental mode participation factor, and $S_{d}\left(T_{\text {eff }}, \zeta_{\text {eff }}\right)$ is the maximum displacement of a linearly-elastic SDF system with effective period, $T_{\text {eff }}$, and effective damping ratio, $\zeta_{\text {eff. }}$ The FEMA-440 CSM includes improved expressions, compared to the ATC-40 CSM, to determine the effective period and effective damping developed by Guyader and Iwan [7]. Consistent with the original ATC-40 procedure, three iterative procedures for estimating the target displacement are also outlined. Finally, a limitation on the strength is imposed to avoid dynamic instability (9).

The improved formulas for effective period and damping ratio in the FEMA-440 document are

$$
\begin{gathered}
T_{\text {eff }}= \begin{cases}{\left[0.2(\mu-1)^{2}-0.038(\mu-1)^{3}+1\right] T_{o} ;} & \mu<4.0, \\
{[0.28+0.13(\mu-1)+1] T_{o} ;} & 4.0 \leq \mu \leq 6.5, \\
{\left[0.89\left(\sqrt{\frac{(\mu-1)}{1+0.05(\mu-2)}}-1\right)+1\right] T_{o} ;} & \mu>6.5,\end{cases} \\
\zeta_{\text {eff }}= \begin{cases}4.9(\mu-1)^{2}-1.1(\mu-1)^{3}+\zeta_{o} ; & \mu<4.0, \\
14.0+0.32(\mu-1)+\zeta_{o} ; & 4.0 \leq \mu \leq 6.5, \\
19\left[\frac{0.64(\mu-1)-1}{0.64(\mu-1)^{2}}\right]\left(\frac{T_{\mathrm{eq}}}{T_{o}}\right)^{2}+\zeta_{o} ; & \mu>6.5 .\end{cases}
\end{gathered}
$$

These formulas apply for periods in the range of 0.2 and $2.0 \mathrm{~s}$. The FEMA-440 document also provides formulas with constants $A$ to $L$ that are specified depending on the forcedeformation relationships (bilinear, stiffness-degrading, and strength-degrading) and the postyield stiffness ratio, $\alpha$; these formulas are not included here for brevity's sake.

\section{Analytical Models}

4.1. Modeling Procedure. Needed for estimating the target displacement is the pushover curve of the building. For this purpose, three-dimensional models of the selected buildings were developed using the structural analysis software Open
System for Earthquakes Engineering Simulation (OpenSees) [10]. Two models were developed for each building: linearlyelastic model for computing the mode shapes and frequencies (or vibration periods), and a nonlinear model for pushover analysis. Gravity loads were included in both models and were applied prior to eigen analysis to compute mode shapes and frequencies or the pushover analysis. Furthermore, $P$-Delta effects were included in both models. The beams, columns, and shear walls in the linear model were modeled using elasticBeam Column element in OpenSees with effective (or cracked) section properties as per the FEMA-356 recommendations [1]. The beams, columns, and shear walls in the nonlinear model were modeled with nonlinearBeamColumn element with fiber section in OpenSees. Contributions to stiffness due to flexural as well as shear effects were included in both models.

The nonlinear element used fiber sections containing confined concrete, unconfined concrete, and steel reinforcing bars to model the axial-flexural behavior, whereas linearelastic behavior was assumed for the shear and torsional behavior. The compressive stress-strain behavior of concrete, both confined and confined, was modeled with Concrete04 material in OpenSees (Figure 2(a)) and tensile strength was ignored. Furthermore, concrete was assumed to completely lose strength immediately after the crushing strain. The crushing strain of the unconfined concrete was selected to be equal to 0.004 and that for confined concrete was selected to be that corresponding to the rupture of confining steel using the well-established Mander model [11]. The stressstrain behavior of steel was modeled with ReinforcingSteel material in OpenSees (Figure 2(b)). Further details of the material models are available in McKenna and Fenves [10]. The nominal strengths of concrete and steel were selected based on the values specified in the structural drawings.

For two of the five selected buildings-Watsonville Commercial Building and Santa Barbara Office Building-the foundation flexibility was expected to significantly influence the response during strong ground shaking because both of these low-rise buildings contained longitudinal and transverse shear walls. The foundation flexibility was included in analytical models of these buildings by attaching six linear springs - three along the $x$-, $y$-, and $z$-translation, two about the $x$ - and $y$-rocking, and one about the $z$-torsion-at the base as per the FEMA-356 recommendations for foundation flexibility modeling [1].

4.2. Validation of Analytical Models. The models developed in this investigation are based on generally accepted engineering practice. Therefore, the difference between the target displacement from various nonlinear static procedures and the value derived from recorded motions of a building would be due to errors due to inaccuracies in modeling as well as nonlinear static procedures. In this investigation, which utilizes data from actual buildings during an earthquake event, it may not be completely possible to isolate the errors from these two sources. However, it is important that the analytical model be as "accurate" as possible to minimize the errors due to modeling. For this purpose, models of selected 


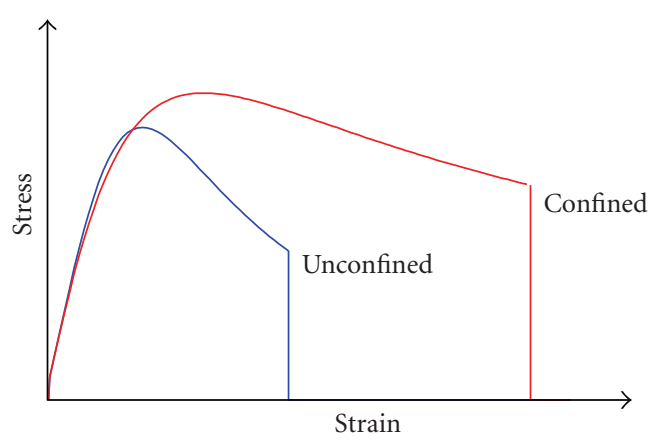

(a) Concrete Model

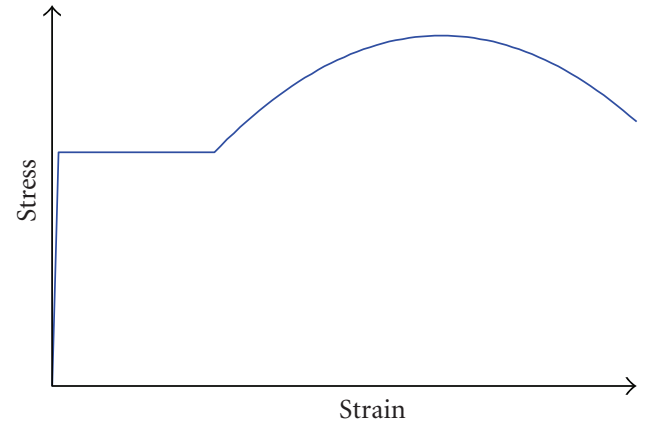

(b) Steel Model

FIgURE 2: Material models used for nonlinear analysis.

buildings used in this investigation were validated by comparing their vibration properties and displacement responses (due to recorded base motions during actual earthquake events) with those observed during actual earthquake events. The following is a description of the procedure used to validate the model of the North Hollywood Hotel. A similar procedure was used to validate models for other buildings.

First, fundamental vibration periods of the building in the longitudinal and transverse directions were identified from recorded motions of the building by using a wellknown transfer function approach (Figure 3). Next, these periods were computed from eigen-analysis of the linearlyelastic model (Figure 4). Finally, the linearly-elastic model was validated by comparing the vibration periods identified from recorded motions and computed from eigen-analysis. Although not identical to the periods identified from recorded motions, the vibration periods from eigen-analysis are close enough for most practical applications: period from eigen-analysis in the longitudinal direction is $2.57 \mathrm{sec}$ compared to the identified value of $2.64 \mathrm{sec}$. It is useful to emphasize again that the linear-elastic model considered in this investigation is based on generally accepted engineering practice and is not intentionally calibrated to match the periods indentified from the recorded motions.

The nonlinear model used in this investigation was first validated by comparing the fundamental vibration period estimated from the pushover curves against the value from eigen-analysis and value identified from recorded motions. For this purpose, the pushover curve was converted to the capacity curve of the equivalent inelastic SDF system by scaling the roof displacement by $1 /\left(\Gamma_{1} \phi_{r 1}\right)$ and base shear by $1 / M_{1}^{*}$ where $\Gamma_{1}$ is the first-mode participation factor, $\phi_{r 1}$ is the first-mode component at the roof (or target node), and $M_{1}^{*}$ is the first-mode effective mass. The fundamental vibration period is estimated by recognizing that initial elastic slope of the capacity curve of the equivalent inelastic SDF system is equal to $\omega_{1}^{2}$ which gives $T_{1}=2 \pi / \omega_{1}$ [12] .

The results presented in Figure 5 indicate that the pushover curve also provides estimates of fundamental vibration periods that are close to the values identified from recorded motions and computed from eigen-analysis of linearly-elastic model. For example, the longitudinal vibration period of $2.78 \mathrm{sec}$ (Figure 5(a)) from pushover curve compares quite well with the value of $2.64 \mathrm{sec}$ identified from recorded motions (Figure 3(a)) and $2.57 \mathrm{sec}$ computed from eigen-analysis of the linear elastic model (Figure 4(a)).

The nonlinear model was further validated by comparing the displacement responses of the model subjected to motions recorded at the base of the building with the displacements derived from recorded motions. The results shown in Figure 6 for the North Hollywood Hotel indicate that the model provides displacement response histories that match quite well with the displacement histories derived from recorded motions.

The vibration periods of selected buildings from the three sources-system identification using recorded motions, eigen-analysis of the linearly-elastic model, and pushover analysis of the nonlinear model-are summarized in Table 2. The presented results indicate that vibration periods from system identification and eigen-analysis of the linear-elastic model match quite well for all buildings. The vibration periods estimated from pushover analysis of the nonlinear model also match quite well with results from the two other sources for three of the five buildings-Imperial County, Sherman Oaks, and North Hollywood. However, the pushover analysis provides longer periods compared to the two other sources for two shear-wall buildings-Watsonville and Santa Barbara.

The longer vibration period from the pushover analysis of the two shear-wall buildings is due to lower initial elastic stiffness of the system during the pushover analysis compared to that in the model used for eigen-analysis. The lower stiffness of the system during pushover analysis is apparently due to lower effective moment of inertia of the shear walls compared to the value of 0.5 times the gross moment of inertia assumed in the model for eigen-analysis of the building. This observation is consistent with that in a recent study [13] which concluded that the factor to convert the gross moment of inertia to the effective moment of inertia is significantly lower than the value of 0.5 specified in the ASCE-41 and FEMA-356 documents. The discrepancy can be particularly large for low values of axial force; experimental data presented in Elwood et al. [13] indicated that the factor can be as low as 0.1 for zero axial force level. Clearly, the vibration period computed based on the effective moment of inertia factor of 0.5 , the value specified in FEMA-356 


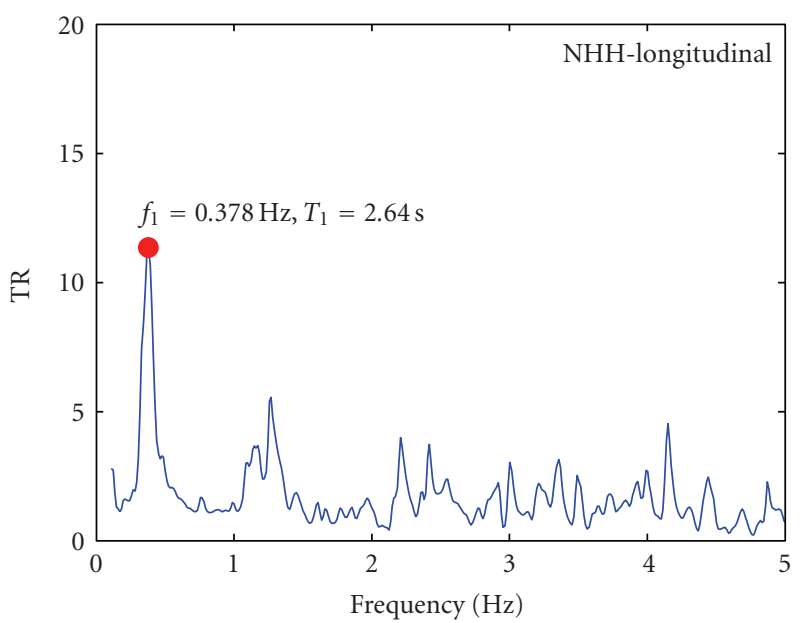

(a)

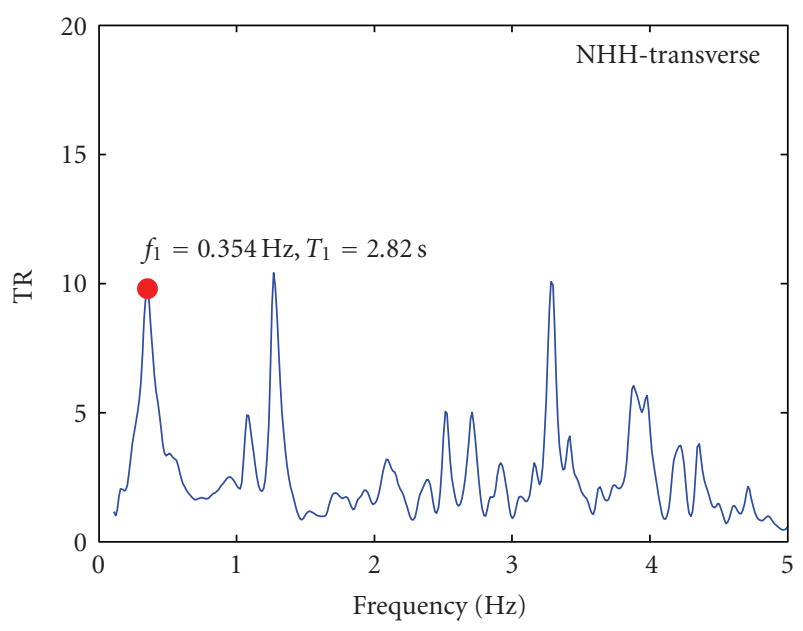

(b)

FIGURE 3: Fundamental vibration period of North Hollywood Hotel identified from recorded motions. (a) Longitudinal direction, and (b) Transverse direction.

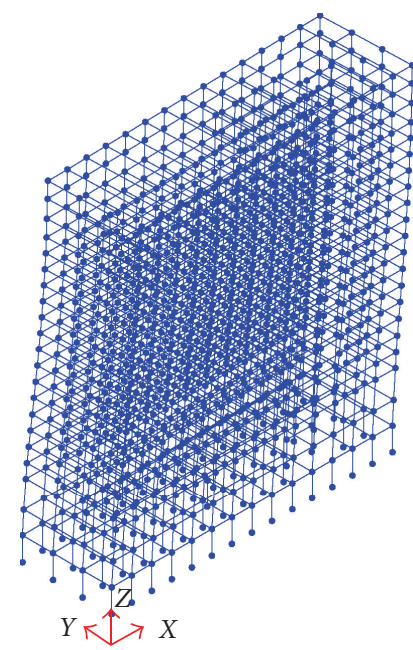

(a) 1st Long. Mode: $T=2.572 \mathrm{~s}$

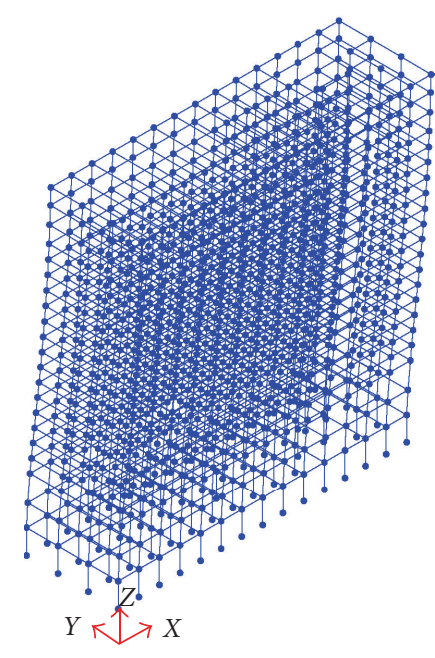

(b) 1st Trans. Mode: $T=2.980 \mathrm{~s}$

Figure 4: Vibration periods and mode shapes of the North Hollywood hotel computed from eigen-analysis of the linear-elastic model. (a) Longitudinal direction, and (b) Transverse direction.

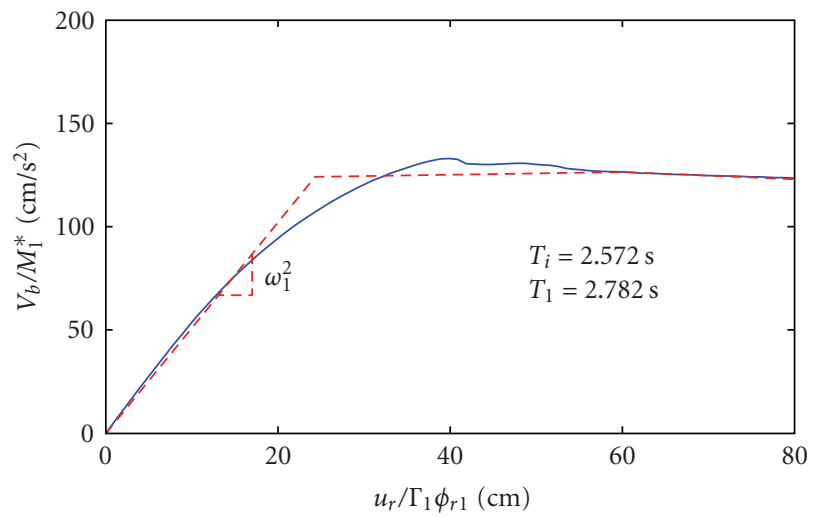

(a)

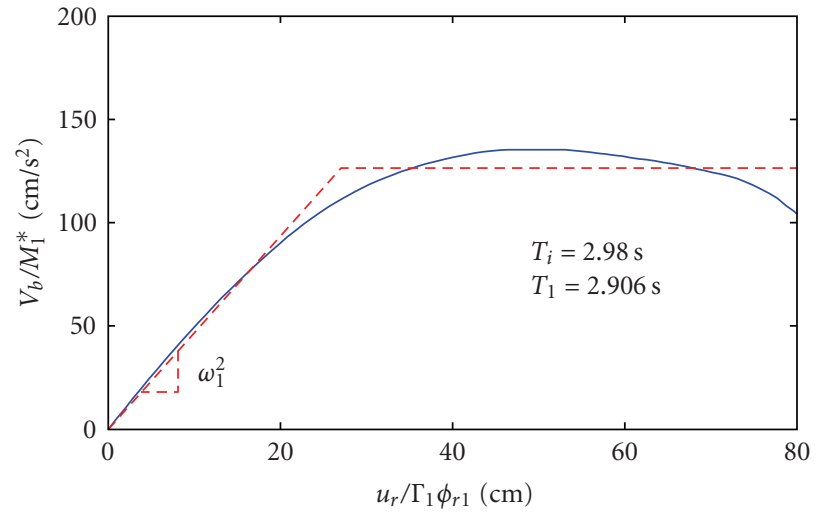

(b)

FIGURE 5: Computation of the fundamental vibration period from capacity curve of the equivalent inelastic SDF systems of the North Hollywood Hotel. (a) Longitudinal direction and (b) Transverse direction. 

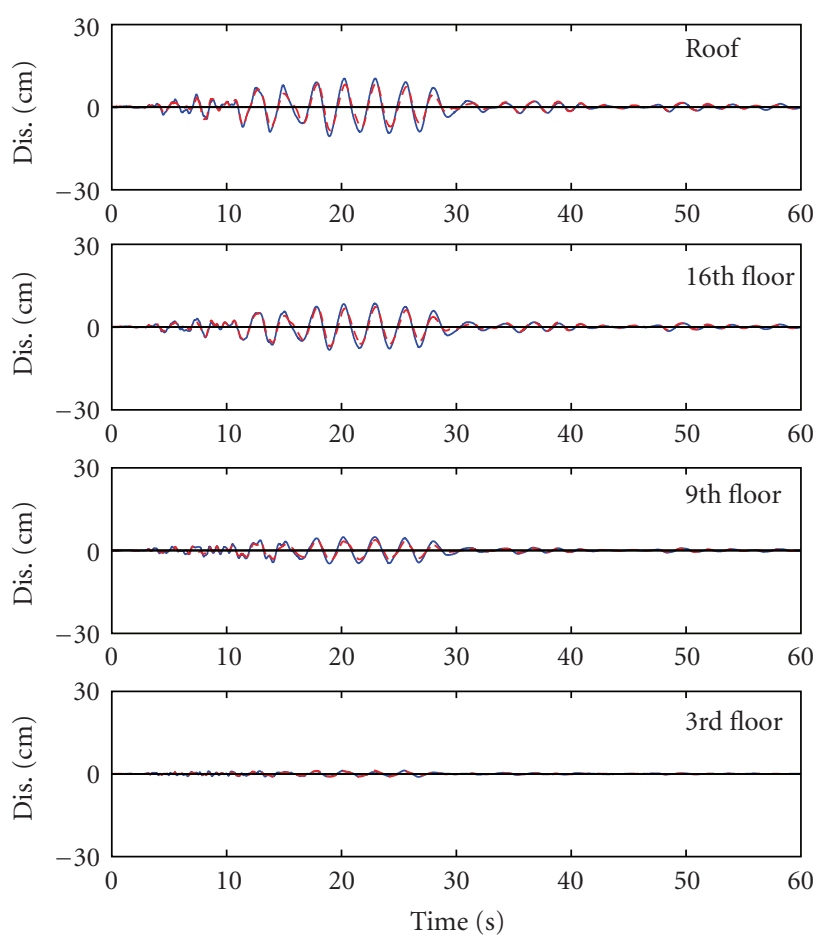

$\begin{array}{ll}\text { - } & \text { Recorded } \\ -- \text { Computed }\end{array}$

(a)
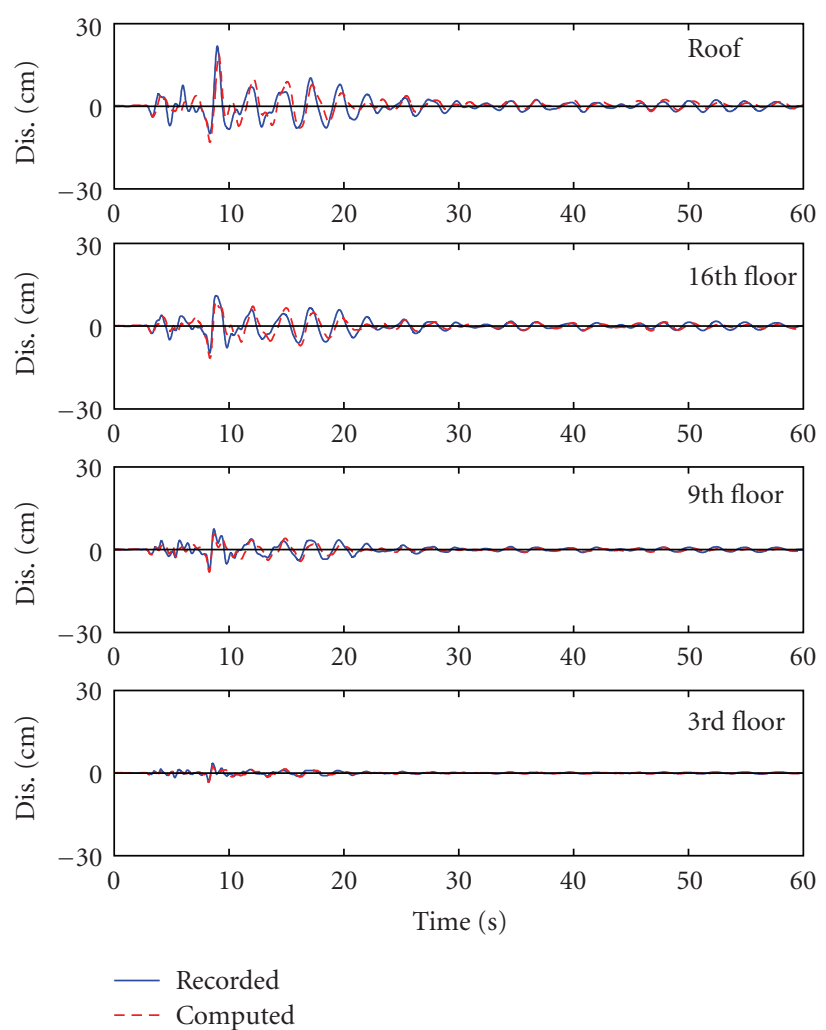

(b)

Figure 6: Comparison of computed and recorded displacements of the North Hollywood Hotel. (a) Longitudinal direction, and (b) Transverse direction.

document, would be much shorter compared to the value computed from the initial elastic slope of the pushover curve which used a fiber-section model with very low axial force for nonlinear beam-column element.

\section{Computation of Target Displacements}

This section presents computation of the target displacement, selected as displacement at the center of the roof, from the four nonlinear static procedures-FEMA-356 CM, ASCE-41 CM, ATC-40 CSM, and FEMA-440 CSM-for each of the selected buildings. Furthermore, reasons for differences in target displacements from various procedures, if any, are discussed. The presented results also include the peak displacement at the center of the roof derived from recorded motions of the building.

The peak roof displacement in the FEMA-356 CM was computed from (1) to (5) with the coefficient $C_{0}$ assumed to be equal to the first-mode participation factor and $C_{2}$ assumed to be 1.0 for framing type 2 defined in the FEMA356 document. The $S_{a}$ needed in (1) and (5) was computed from the elastic response spectrum of the acceleration recorded at the base of the building in the appropriate direction at vibration period $T_{e}$. The peak roof displacement in the ASCE-41 CM was similarly computed from (6) to (8).

The peak roof displacement in the ATC-40 CSM is computed from (11) with $C_{0}$ assumed to be equal to the first- mode participation factor and $S_{d}$ computed from damped elastic response spectrum of the acceleration recorded at the base of the building in the appropriate direction. Because computation of $T_{\mathrm{eq}}$ and $\zeta_{\mathrm{eq}}$ in (12) needs displacement ductility factor, $\mu$, of the equivalent SDF system, the estimation of the target displacement in the ATC-40 CSM requires an iterative procedure. Although the ATC-40 document specified three different procedures, the graphical ATC-40 Procedure is used in this investigation to compute $S_{d}$. For this purpose, a curve of locus of performance points is developed. Each point on this curve is the pair of displacement and pseudoacceleration of an equivalent SDF system with $T_{\mathrm{eq}}$ and $\zeta_{\text {eq }}$ computed for a selected value of $\mu$. The value of $S_{d}$ to be used in (11) is selected as the displacement at the intersection of the curve of locus of performance points and the capacity curve of the equivalent inelastic SDF system of the building. The capacity curve of the of the equivalent inelastic SDF system is obtained from the pushover curve of the building by the previously described procedure.

The peak roof displacement in the FEMA-440 CSM is computed from (13) with $S_{d}$ estimated from a procedure similar to that described for the ATC-40 CSM with two differences. First, values of $\zeta_{\text {eff }}$ and $T_{\text {eff }}$ in the FEMA-440 CSM are computed from (14). Second, the pseudoacceleration of an equivalent SDF system is modified by a factor to account for the differences between the effective period being used in the FEMA-440 CSM and the secant period used in the 
TABle 2: Comparison of fundamental vibration periods (sec) from system identification, linear-elastic model, and pushover analysis of nonlinear model.

\begin{tabular}{|c|c|c|c|c|c|c|}
\hline \multirow{2}{*}{ Building } & \multicolumn{3}{|c|}{ Longitudinal direction } & \multicolumn{3}{|c|}{ Transverse direction } \\
\hline & System ID & Linear model & Nonlinear model & System ID & Linear model & Nonlinear model \\
\hline Imperial County & N/A & N/A & N/A & 0.41 & 0.41 & 0.48 \\
\hline Sherman Oaks & 2.93 & 2.67 & 2.51 & 2.93 & 2.94 & 2.62 \\
\hline North Hollywood & 2.64 & 2.57 & 2.78 & 2.82 & 2.98 & 2.91 \\
\hline Watsonville & 0.24 & 0.27 & 0.46 & 0.30 & 0.31 & 0.41 \\
\hline Santa Barbara & 0.16 & 0.15 & 0.23 & 0.20 & 0.18 & 0.28 \\
\hline
\end{tabular}

ATC-40 CSM. Further details of this procedure, denoted as the modified ADRS procedure, are available in the FEMA440 document [3].

Typically, the locus of performance points in the ATC-40 and FEMA-440 CSM is plotted on the capacity curve for the equivalent inelastic SDF system to estimate the displacement $S_{d}$. In this investigation, the displacement $S_{d}$ (or $S_{a}=$ $\left.S_{d} /\left(2 \pi / T_{e}\right)^{2}\right)$ is used to compute peak roof displacement using (1), (6), (11), and (13) for FEMA-356 CM, ASCE-41 CM, ATC-40 CSM, and FEMA-440 CSM, respectively, which is then plotted on the pushover curve of the building. Such a plot permits direct comparison of target displacement from the CSM procedure and the recorded displacement.

The pushover curves needed in implementing the selected procedures were developed for fundamental-mode height-wise distribution of lateral loads defined by $\mathbf{s}=$ $\eta \mathbf{m} \phi_{1}$ in which $\mathbf{m}$ is the mass matrix, $\phi_{1}$ is the vector of fundamental mode shape, and $\eta$ is the load multiplier during pushover analysis. The fundamental mode distribution is the only distribution specified in the ATC-40, FEMA440, and ASCE-41 pushover procedures whereas it is one of the distributions specified in the FEMA-356 pushover procedure.

5.1. Imperial County Services Building. The Imperial County Services Building is unique among the five selected building in this investigation because it collapsed during the selected earthquake. The strength and stiffness of this building was provided primarily by moment-resisting frames in the longitudinal direction and shear walls in the transverse direction. The postearthquake investigation [15] as well the pushover analysis [14] indicated that this building collapsed in the longitudinal direction due to concrete crushing at bases of columns in the moment-resisting frames. Obviously, the four procedures could not be applied to estimate peak displacement of this building in the longitudinal direction. The collapse of the building in the longitudinal direction, however, did not significantly influence its stiffness and strength in the transverse direction because shear walls, which provide most of the stiffness and strength in this direction, did not exhibit significant damage. Therefore, these procedures could be applied to estimate the peak roof displacement in the transverse direction. However, the results for this building should be viewed with care as these results include errors associated with the modeling and analytical procedure, mentioned previously, as well as due to effects of failure in the longitudinal direction on response in the transverse direction.

The results presented in Figure 7 for the Imperial County Services Building due to the 1979 Imperial Valley earthquake show that the FEMA-356 CM, ASCE-41 CM, ATC-40 CSM, and FEMA-440 CSM lead to target roof displacement of $6.98 \mathrm{~cm}, 7.60 \mathrm{~cm}, 5.64 \mathrm{~cm}$, and $5.46 \mathrm{~cm}$, respectively; the peak roof displacement derived from recorded motions during this earthquake is $5.78 \mathrm{~cm}$. The differences between the peak roof displacements from the FEMA-356 CM and the ASCE-41 CM are clearly due to different values of the coefficient that converts the peak displacement of a linearelastic SDF system to that of an inelastic SDF system between the two CM procedures. Recall that the factor to convert the peak displacement of a linear-elastic SDF system to that of an inelastic SDF system is equal to $C_{1} C_{2} C_{3}$ for the FEMA-356 CM (1) and $C_{1} C_{2}$ for the ASCE-41 CM (6). Furthermore, values of the individual coefficients between the two procedures differ for the same value of $R$ and $T_{e}$ (see (3) and (4) for the FEMA-356 CM, and (7) and (8) for the ASCE-41 CM). Although quite different in implementation details, the two CSM procedures-ATC-40 and FEMA-440led to very similar estimates of target displacement for this building.

5.2. Sherman Oaks Commercial Building. The presented results indicate that the two CM procedures-FEMA-356 and ASCE-41-provide identical estimate of the peak roof displacements of the Sherman Oaks building: the roof displacement is $27.98 \mathrm{~cm}$ (Figures 8(a) and 8(b)). Such is the case because the coefficient $C_{1}$ in the FEMA-356 CM (3) and $C_{1}$ and $C_{2}$ in the ASCE-41 CM ((7) and (8)) are all equal to unity because fundamental longitudinal vibration period of this building is the longer than the threshold period value, and $C_{3}$ in the FEMA-356 CM (4) is equal to unity due to positive postyield stiffness. The ATC-40 CSM and FEMA440 CSM provide peak roof displacement of $24.26 \mathrm{~cm}$ and $27.09 \mathrm{~cm}$, respectively (Figures 8(c) and 8(d)). Unlike the two CM procedures, the two CSM procedures lead to slightly different values of the roof displacement. This difference is due to different values of effective period and damping ratio used in these CSM procedures (see (12) and (14)). The peak roof displacement derived from recorded motions of this building during the selected earthquake is $33.6 \mathrm{~cm}$.

All four procedures lead to identical peak roof displacement in the transverse direction: the peak roof displacement 


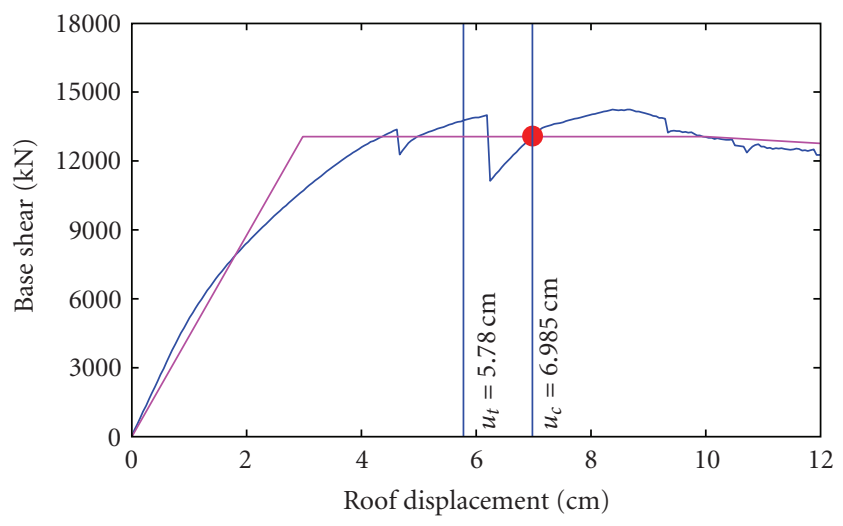

(a) FEMA-356 CM

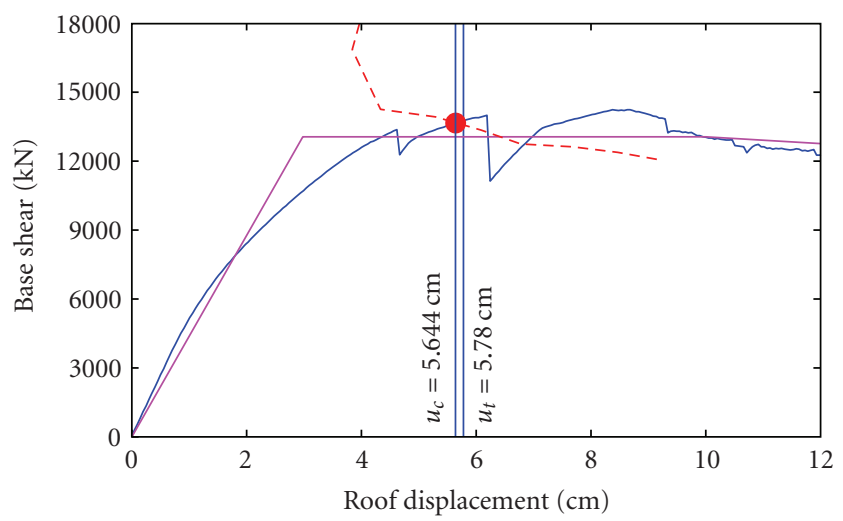

(c) ATC-40 CSM

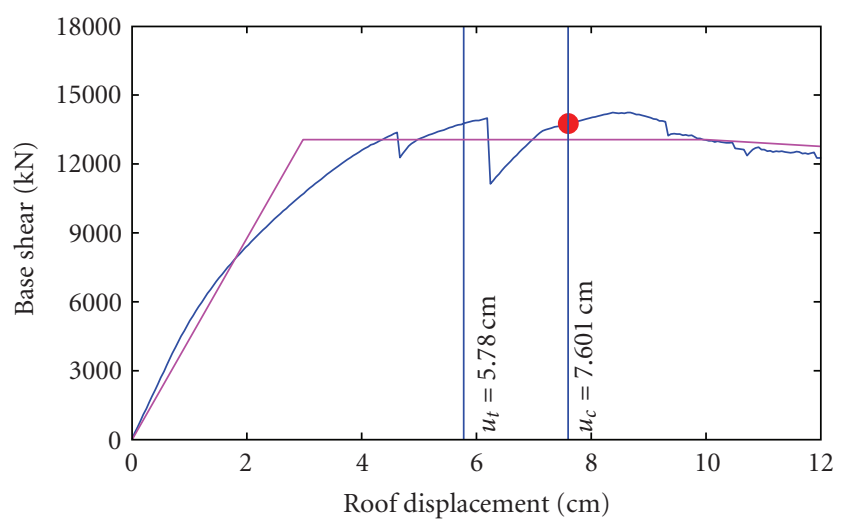

(b) ASCE-41 CM

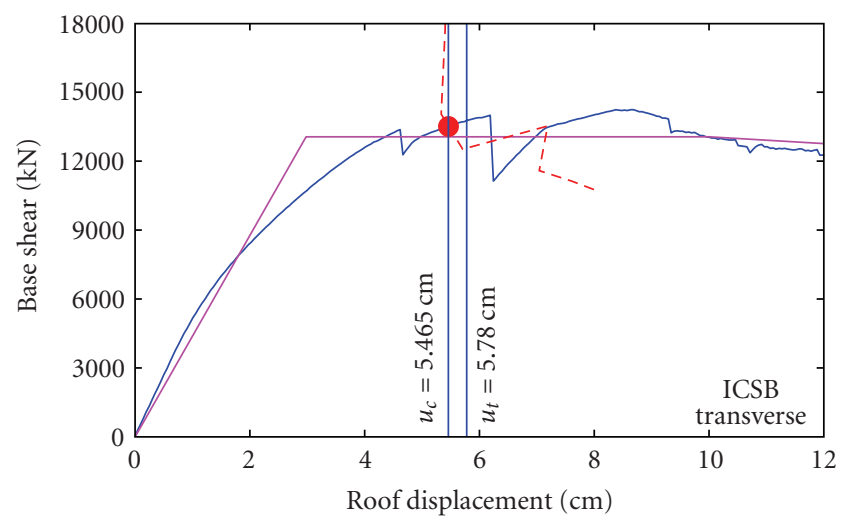

(d) FEMA-440 CSM

Figure 7: Computation of the roof displacement from the FEMA-356 CM, ASCE-41 CM, ATC-40 CSM, and FEMA-440 CSM in the transverse direction of the Imperial County Services Building.

is equal to $17.98 \mathrm{~cm}$ (Figure 9). Such is the case because the building in the transverse direction remains in the linear elastic range during the 1994 Northridge earthquake. Recall that the coefficients $C_{1}, C_{2}$, and $C_{3}$ in the FEMA356 NSP ((3) and (4)) as well as the coefficients $C_{1}$ and $C_{2}$ in the ASCE-41 NSP ((7) and (8)) are equal to one for a linearly-elastic system. Furthermore, the vibration period and damping ratio in the ATC-40 CSM and FEMA-440 CSM remain equal to that of a linear-elastic system for $\mu=1$ (see (12) and (14)). The peak roof displacement derived from the recorded motions of this building in the transverse direction is $22.71 \mathrm{~cm}$.

The presented results also indicate that the peak roof displacements from the four procedures for the Sherman Oaks building are less than those from recorded motions. Such is the case because these procedures attempt to capture the response only due to the fundamental mode. Such procedures, obviously, cannot capture the response due to higher modes; several higher modes contribute to the response of the Sherman Oaks Commercial Building [14].

5.3. North Hollywood Hotel. Although strongly shaken, the North Hollywood Hotel remained within the linear-elastic range in both the longitudinal and transverse directions during the 1994 Northridge earthquake. The results for this building are presented only for the transverse directionthe direction with the larger roof displacement. As noted previously for the Sherman Oaks building in the transverse direction, all four procedures provide estimates of peak roof displacement that is identical and equal to $14.33 \mathrm{~cm}$ (Figure 10). The peak roof displacement derived from recorded motions of this building is $17.46 \mathrm{~cm}$. For reasons similar to those identified previously for the Sherman Oaks Commercial Building, the lower estimate from the four procedures is due to the inability of these procedures to capture higher mode effects that contribute significantly to the transverse response of this building [14].

5.4. Watsonville Commercial Building. The results presented in Figure 11 for the Watsonville Commercial Building indicate that the estimate of the peak roof displacements in the longitudinal direction from the FEMA-356 CM, ASCE$41 \mathrm{CM}$, ATC-40 CSM, and FEMA-440 CSM is $3.13 \mathrm{~cm}$, $3.01 \mathrm{~cm}, 3.12 \mathrm{~cm}$, and $2.98 \mathrm{~cm}$, respectively. The peak roof displacement derived from recorded motions of this building is $3.33 \mathrm{~cm}$. As noted previously for the Imperial County Services Building, the two CM procedures provide different estimates of peak roof displacement because various coefficients in these procedures differ for shorter vibration 


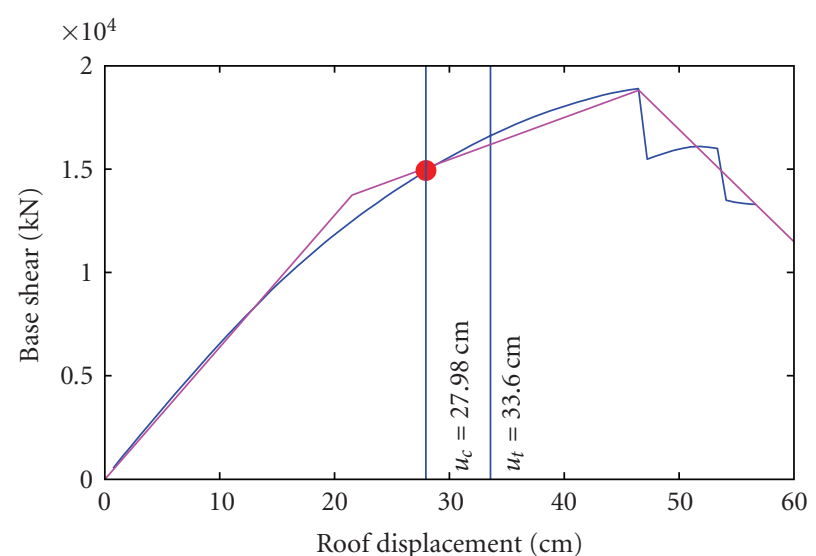

(a) FEMA-356 CM

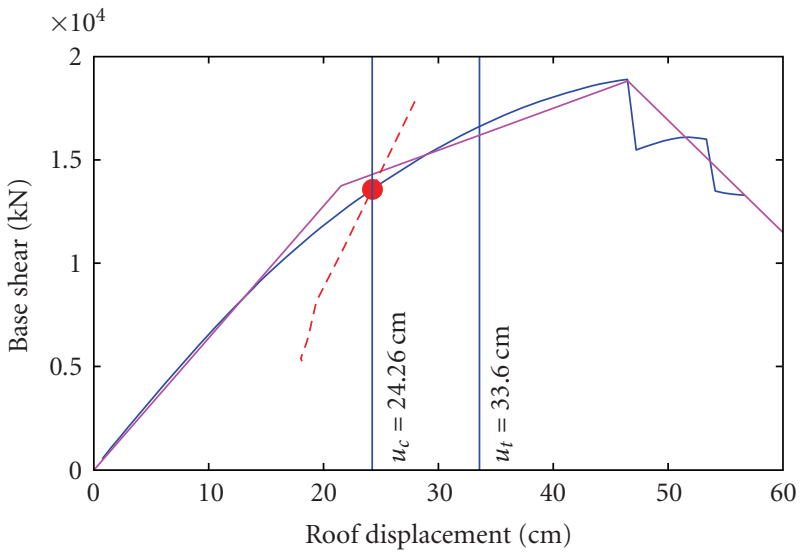

(c) ATC-40 CSM

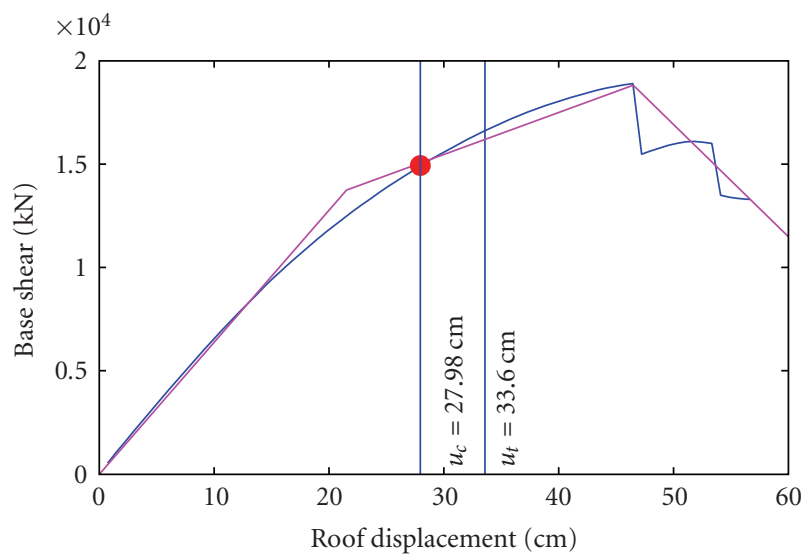

(b) ASCE-41 CM

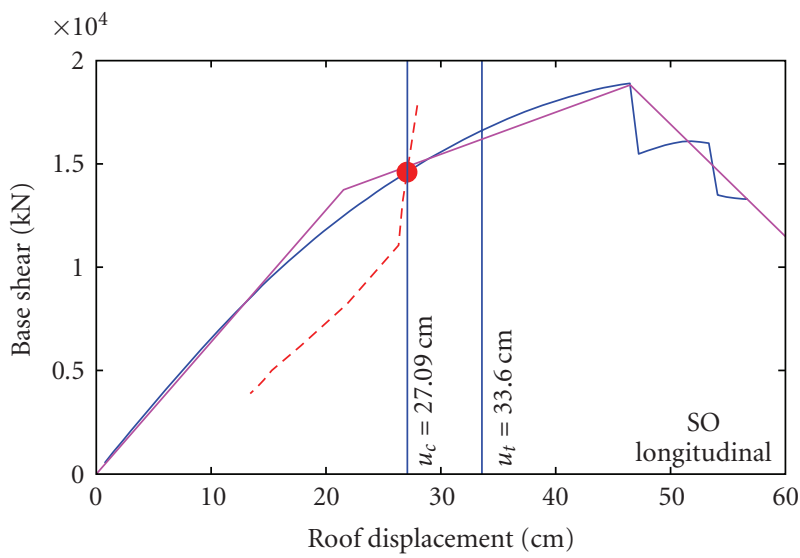

(d) FEMA-440 CSM

FIGURE 8: Computation of the roof displacement from the FEMA-356 CM, ASCE-41 CM, ATC-40 CSM, and FEMA-440 CSM in the longitudinal direction of the Sherman Oaks Commercial Building.

periods; the fundamental longitudinal vibration period of this building is $0.27 \mathrm{sec}$ (Table 2).

The building remained essentially in the linear elastic range in the transverse direction (Figure 12). The two CM procedures provide estimates of the peak roof displacements that are essentially identical: the FEMA-356 CM provides a value of $2.75 \mathrm{~cm}$ and ASCE- $41 \mathrm{CM}$ gives a value of $2.68 \mathrm{~cm}$ (Figures 12(a) and 12(b)). The ATC-40 CSM provides an estimate of the peak roof displacement of $2.42 \mathrm{~cm}$ (Figure 12(c)) whereas the value from the FEMA-440 CSM is $2.76 \mathrm{~cm}$ (Figure 12(d)). The peak roof displacement of this building derived from its recorded motion is $1.93 \mathrm{~cm}$.

Unlike the peak roof displacements of the Sherman Oaks Commercial Building and the North Hollywood Hotel, the two CM or the two CSM procedures do not provide an identical estimate of the peak roof displacement of the Watsonville Commercial Building in the transverse direction even though the building remains within the linear-elastic range (Figure 12). This occurs due to the discrepancy between the effective fundamental vibration period estimated from (2) and the vibration period estimated from the pushover curve (Table 2), and the actual damping ratio and the damping ratio of the linear-elastic system used in this investigation.
5.5. Santa Barbara Office Building. Although strongly shaken during the 1978 Santa Barbara earthquake, the Santa Barbara Office Building remained essentially within the linear-elastic range in both directions. For reasons of brevity, the computation of the target displacement from the four procedures is presented only in the longitudinal direction. The presented results indicate that estimate of the roof displacement in the longitudinal direction from the FEMA-356 CM, ASCE-41 CM, ATC-40 CSM, and FEMA- 440 CSM is $0.36 \mathrm{~cm}, 0.35 \mathrm{~cm}$, $0.57 \mathrm{~cm}$, and $0.56 \mathrm{~cm}$, respectively, (Figure 13). The peak value of the roof displacement derived from recorded motion is $0.68 \mathrm{~cm}$. The four procedures do not provide identical estimates of the peak roof displacements, even though the building remained within linear elastic range because of reasons noted previously for the Watsonville Commercial Building.

\section{Variability in Target Displacement}

The estimates of the target displacement from the four nonlinear static procedures-FEMA-356 CM, ASCE-41 CM, ATC-40 CSM, and FEMA-440 CSM-along with the peak roof displacement derived from recorded motions of the 


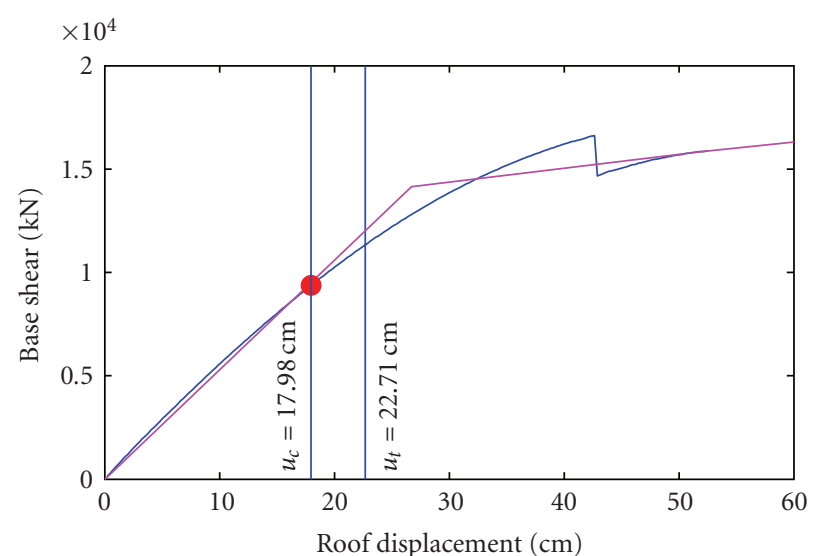

(a) FEMA-356 CM

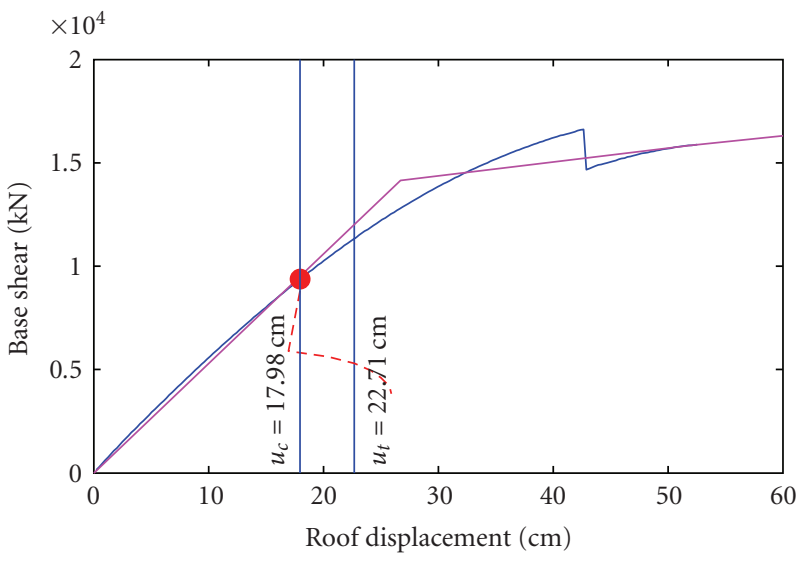

(c) ATC-40 CSM

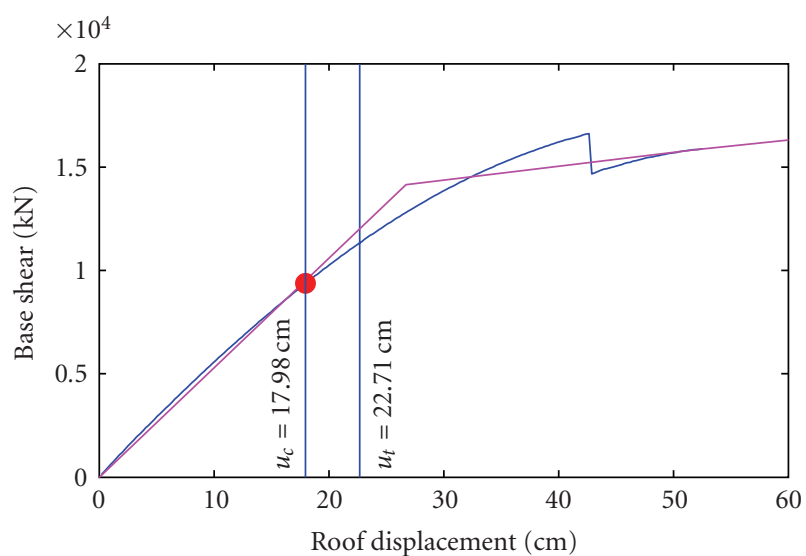

(b) ASCE-41 CM

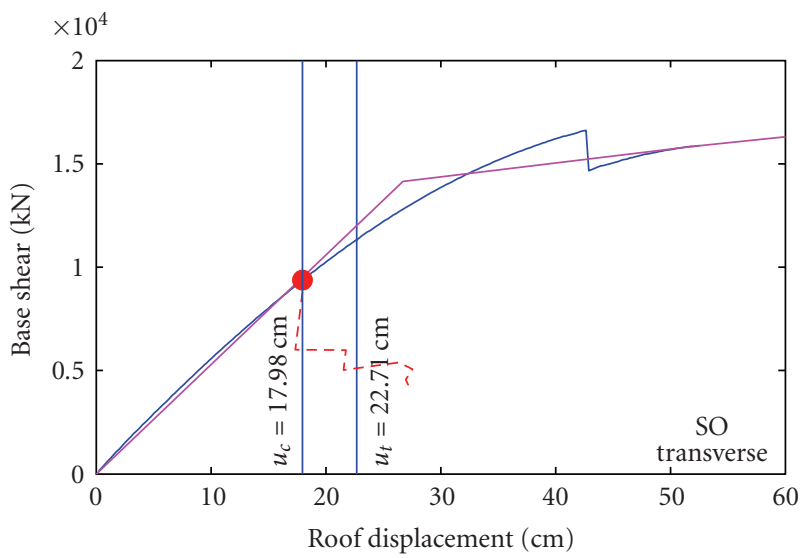

(d) FEMA-440 CSM

Figure 9: Computation of the roof displacement from the FEMA-356 CM, ASCE-41 CM, ATC-40 CSM, and FEMA-440 CSM in the transverse direction of the Sherman Oaks Commercial Building.

selected buildings are summarized in Table 3 in the longitudinal direction and Table 4 in the transverse direction. These results permit the following important observations about variability of target displacement estimates from various nonlinear static procedures.

First, various nonlinear static procedures provide identical estimates of target displacement of long-period buildings that remain within the linear elastic range (see North Hollywood Hotel in the longitudinal direction in Table 3, and Sherman Oaks Commercial Building and North Hollywood Hotel in the transverse direction in Table 4). This is consistent with the expectation that nonlinear static procedures should provide identical estimates for buildings responding in the linear elastic range.

Second, various nonlinear static procedures may provide different estimates of target displacement of short-period shear-wall buildings that remain within the linear elastic range (see Santa Barbara building in the longitudinal direction in Table 3 and Watsonville and Santa Barbara buildings in the transverse direction in Table 4). This occurs because of the sensitivity of the peak displacement of the equivalent SDF system to period and damping in the short-period range. Recall that there may be a slight discrepancy in the effective fundamental vibration period estimated from (2) and the vibration period estimated from the pushover curve for these buildings (Table 2), and the actual damping ratio and the damping ratio of the linear-elastic system used in this investigation. It is useful to point out that the large variability noted here is due to use of response spectrum for individual ground motion, which can be very jagged in the short-period range; this variability would be much less if a smooth design spectrum is used.

Finally, the variability in the target displacement of longperiod building responding in the nonlinear range is much smaller compared to short-period buildings responding in the nonlinear range. For example, the target displacement of the long-period Sherman oaks building in the longitudinal direction from the four nonlinear static procedures varies from $27.98 \mathrm{~cm}$ to $24.26 \mathrm{~cm}$ (Table 3), a variation of about $13 \%$, whereas that for the short-period Imperial County Services building in the transverse direction varies from $7.60 \mathrm{~cm}$ to $5.46 \mathrm{~cm}$ (Table 4), a variation of about $28 \%$. This is the case because of sensitivity of various coefficients in the $\mathrm{CM}$ procedure and the equivalent period and damping in the CSM procedures to degree of nonlinearity, that is, value of $R$. 


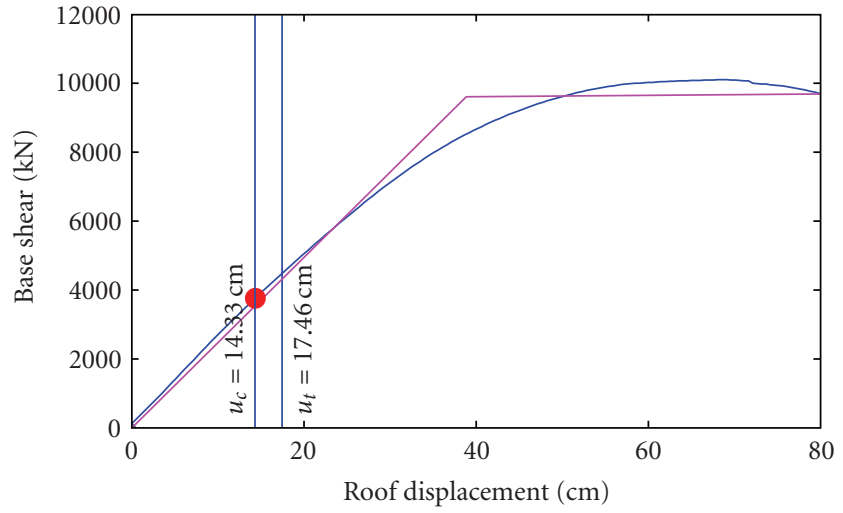

(a) FEMA-356 CM

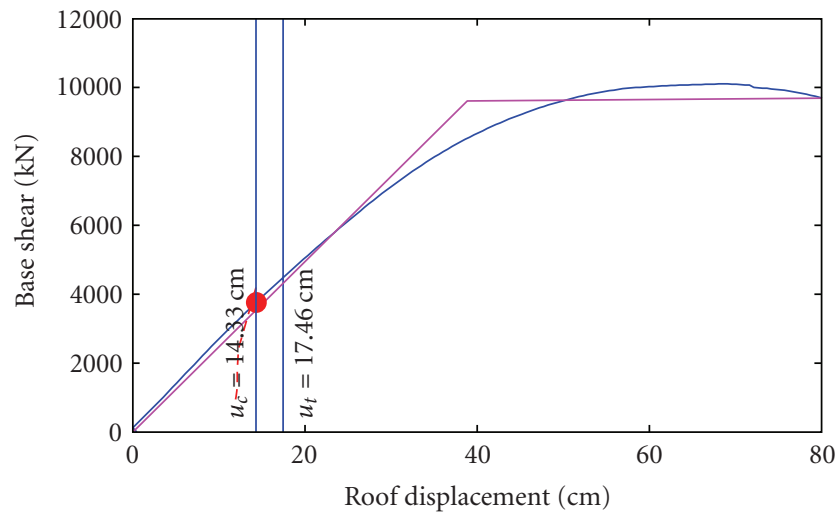

(c) ATC-40 CSM

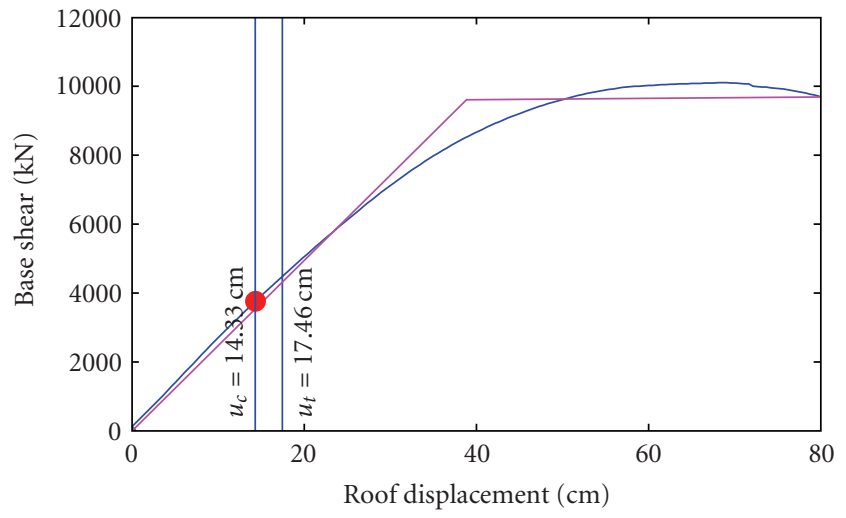

(b) ASCE-41 CM

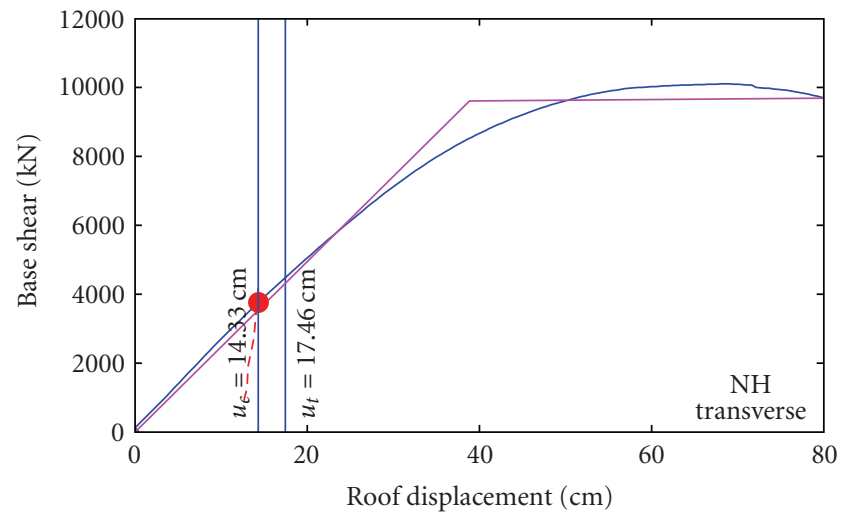

(d) FEMA-440 CSM

Figure 10: Computation of the roof displacement from the FEMA-356 CM, ASCE-41 CM, ATC-40 CSM, and FEMA-440 CSM in the transverse direction of the North Hollywood Hotel.

TAble 3: Peak roof displacement estimated from four nonlinear static procedures and derived from recorded motions in longitudinal direction; all values of displacements are in $\mathrm{cm}$.

\begin{tabular}{lccccc}
\hline Building & & \multicolumn{2}{c}{ Nonlinear static procedure } \\
& FEMA-356 CM & ASCE-41 CM & ATC-40 CSM & FEMA-440 CSM & Recorded \\
\hline Imperial County & N/A & N/A & N/A & N/A \\
Sherman Oaks & 27.98 & 27.98 & 24.26 & 27.09 & 33.60 \\
North Hollywood & 10.17 & 10.17 & 10.17 & 3.12 & 2.98 \\
Watsonville & 3.13 & 3.01 & 0.57 & 0.56 & 3.33 \\
Santa Barbara & 0.36 & 0.35 & & & 0.68 \\
\hline
\end{tabular}

TABLE 4: Peak roof displacement estimated from four nonlinear static procedures and derived from recorded motions in transverse direction; all values of displacements are in $\mathrm{cm}$.

\begin{tabular}{lccccc}
\hline \multirow{2}{*}{ Building } & & & Nonlinear static procedure & \\
& FEMA-356 CM & ASCE-41 CM & ATC-40 CSM & FEMA-440 CSM & Recorded \\
\hline Imperial County & 6.98 & 7.60 & 5.64 & 5.46 & 17.98 \\
Sherman Oaks & 17.98 & 17.98 & 17.98 & 14.33 & 22.71 \\
North Hollywood & 14.33 & 14.33 & 14.33 & 2.76 & 17.46 \\
Watsonville & 2.75 & 2.68 & 1.41 & 1.93 \\
Santa Barbara & 1.06 & 0.92 & 1.06 & 1.28 \\
\hline
\end{tabular}




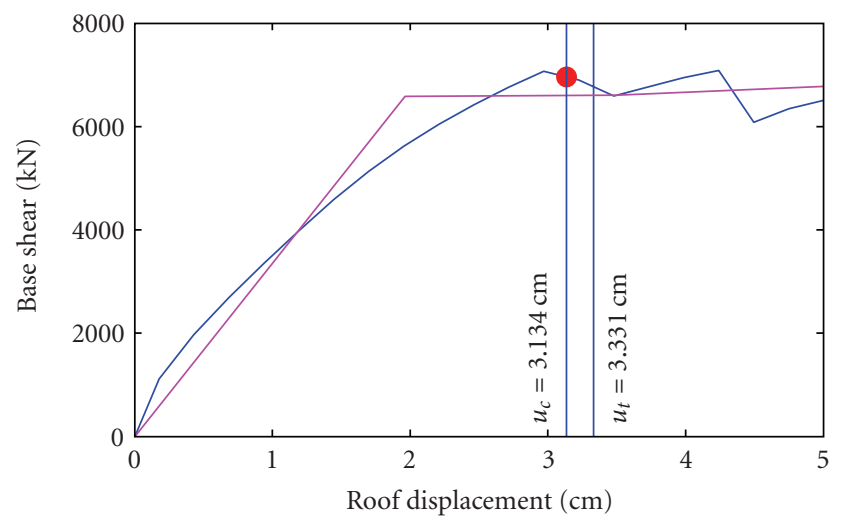

(a) FEMA-356 CM

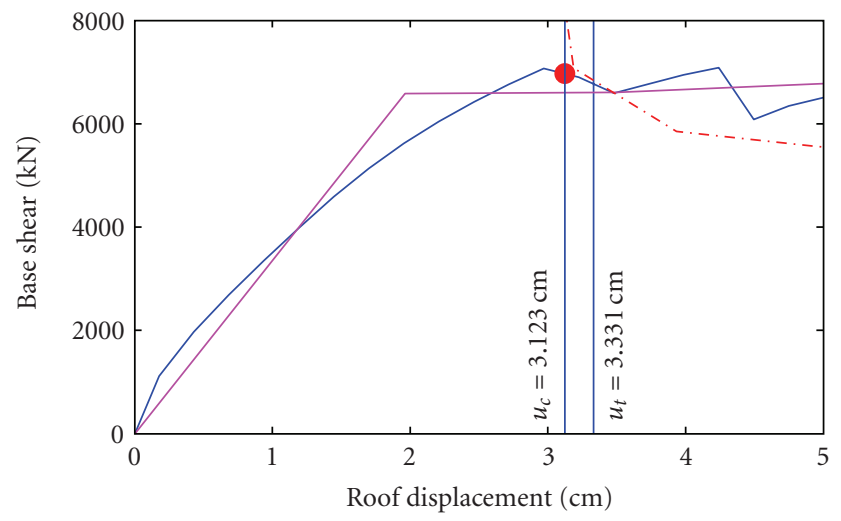

(c) ATC-40 CSM

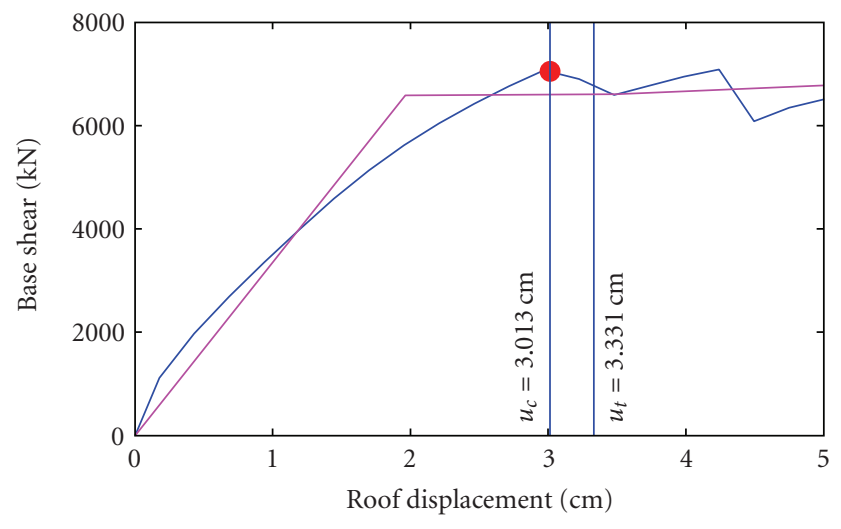

(b) ASCE-41 CM

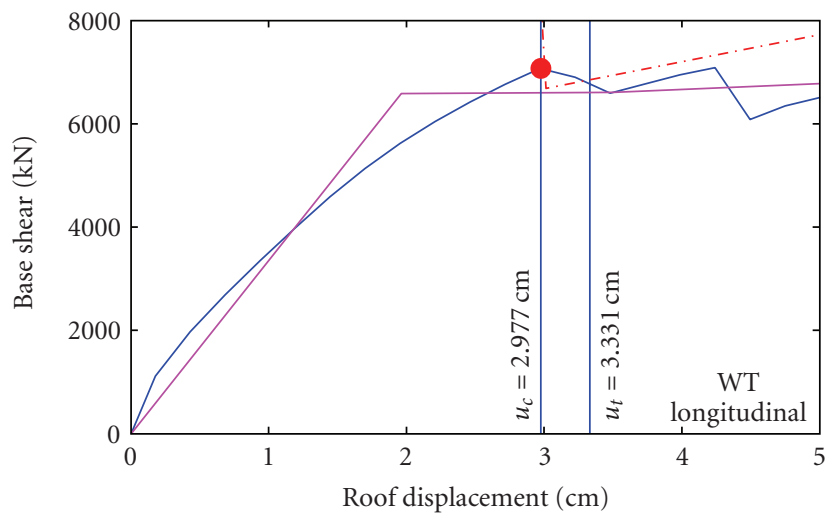

(d) FEMA-440 CSM

Figure 11: Computation of the roof displacement from the FEMA-356 CM, ASCE-41 CM, ATC-40 CSM, and FEMA-440 CSM in the longitudinal direction of the Watsonville Commercial Building.

\section{Accuracy of Target Displacement Prediction}

Figure 14 shows the percent error in the target (or roof) displacement from the four procedures. The percentage errors is defined as the difference between the target roof displacement estimated from a nonlinear static procedure and the peak roof displacement derived from recorded motions during a selected earthquake. The results are presented for Imperial County Services Building in the transverse direction (IC-NS), Sherman Oaks Commercial Building in the longitudinal and transverse directions (SO-EW and SO-NS), North Hollywood Hotel in the longitudinal and transverse directions (NH-EW and NH-NS), Watsonville Commercial Building in the longitudinal and transverse directions (WTEW and WT-NS), and Santa Barbara Office Building in the longitudinal and transverse directions (SB-EW and SB-NS). These results permit an improved understanding of the following question: can the engineering profession "accurately" predict the response of a real building during an earthquake event using currently available modeling techniques and pushover analysis procedures?

The presented results indicate that the current nonlinear static procedure lead to target displacement prediction which may differ significantly from the value observed during an earthquake: the errors range from about 50\% underestimation, for example, as is the case for FEMA-356 CM and ASCE-41 CM for the Santa Barbara Office Building in the longitudinal direction (see SB-EW in Figure 14), to about $40 \%$ over-estimation, for example, ATC-40 CSM and FEMA440 CSM for the Watsonville Commercial Building in the transverse direction (see WT-NS in Figure 14).

Among the two CM procedures, the ASCE- $41 \mathrm{CM}$, which is based on the improvements suggested recently in the FEMA-440 document, does not necessarily provide a better prediction. For example, the ASCE-41 CM leads to larger overestimation for the Imperial County Services Building (see IC-NS in Figure 14) and larger underestimation for the Santa Barbara Office Building (see SB-EW and SB-NS in Figure 14) when compared to the results from the FEMA-356 CM.

Similarly, the FEMA-440 CSM, which is intended to be an improvement over the ATC-40 CSM, may not necessarily lead to better prediction of peak roof displacement. This becomes apparent from Figure 14, where the FEMA-440 CSM either provides a prediction that is slightly worse (see WT-EW and SB-EW in Figure 14) or much worse (see WTNS in Figure 14) prediction compared to the ATC-40.

Finally, there is no clear evidence of whether the CM procedure (FEMA-356 or ASCE-41) or the CSM procedure (ATC-40 or FEMA-440) provides a better prediction of peak roof displacement when compared with the value derived from recorded motions. The CSM procedure leads to better 


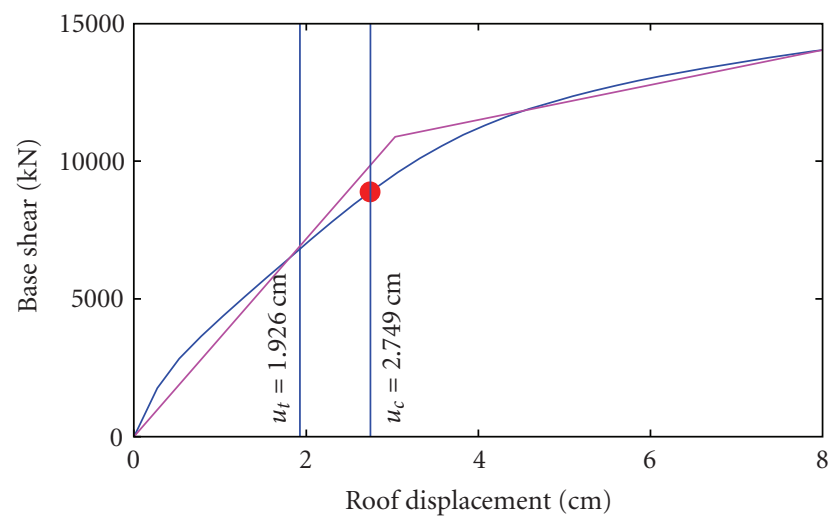

(a) FEMA-356 CM

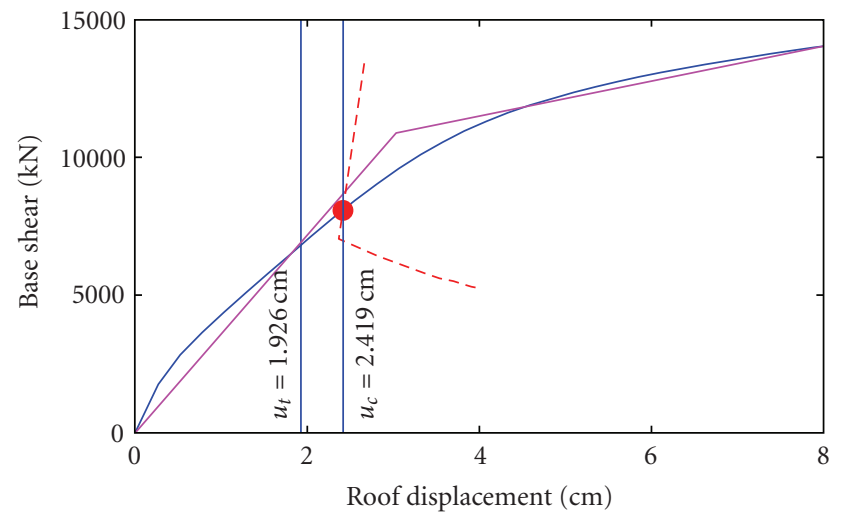

(c) ATC-40 CSM

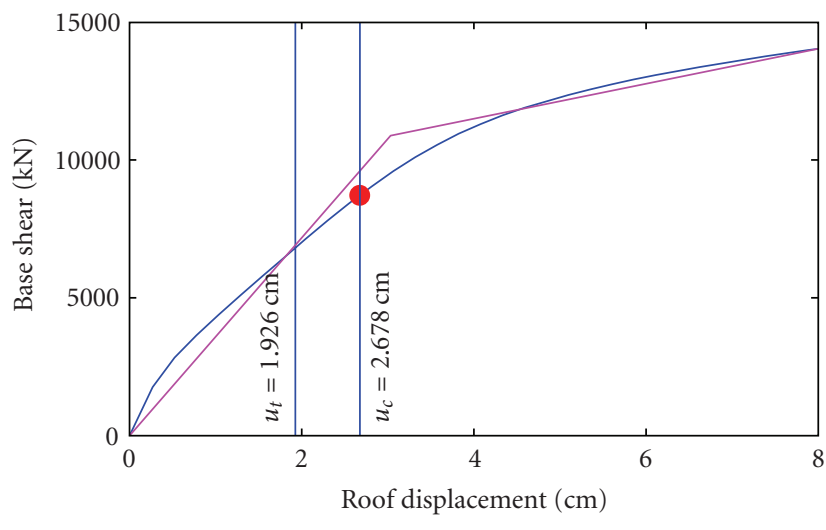

(b) ASCE-41 CM

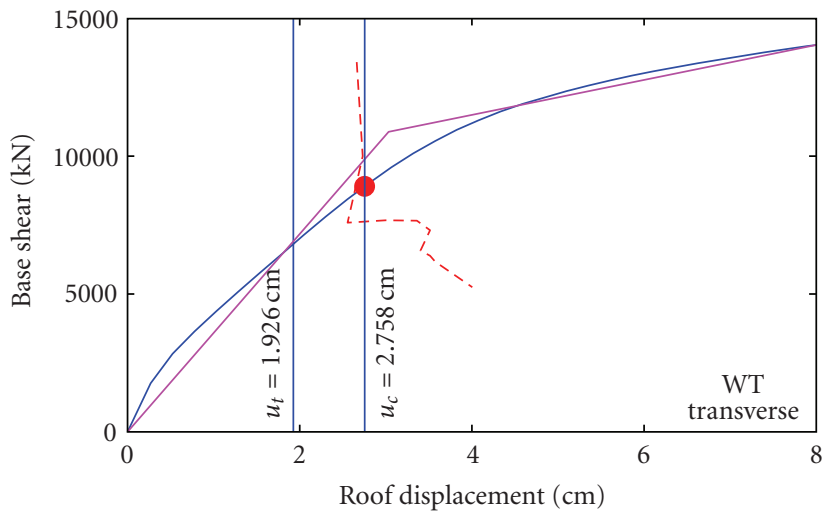

(d) FEMA-440 CSM

FIgure 12: Computation of the roof displacement from the FEMA-356 CM, ASCE-41 CM, ATC-40 CSM, and FEMA-440 CSM in the transverse direction of the Watsonville Commercial Building.

prediction for some buildings (see IC-NS and SB-EW in Figure 14) but worse for others (see SO-EW in Figure 14) compared to the CM procedure. For other buildings, the two procedures lead to essentially similar levels of accuracy (see SO-NS, NH-EW, and NH-NS in Figure 14).

\section{Conclusions}

This investigation compared the target roof displacement computed from the four currently used proceduresFEMA-356 CM, ASCE-41 CM, ATC-40 CSM, and FEMA440 CSM - with the peak roof displacement derived from recorded motions of five reinforced-concrete buildings with the aim of developing an improved understanding of the following two questions: (1) how much does the target displacement varies among the four nonlinear static procedures? and (2) can the engineering profession "accurately" predict the response of a real building during an earthquake event using currently available modeling techniques and pushover analysis procedures? The models of selected buildings utilized in this investigation are developed using generally accepted engineering practice. These models were validated but not intentionally calibrated against the recorded data. This comparison has led to the following conclusions.
The nonlinear static procedures may lead to significantly different estimates of target displacement, particularly for short-period buildings responding in the nonlinear range; the largest variation noted in this investigation approached $28 \%$ for the Imperial County Services building. The variation was much smaller for long-period buildings responding in the nonlinear range. These observations are unlikely to be affected by the inaccuracies associated with modeling errors because the same model was used during implementation of these procedures.

The current nonlinear static procedures, when applied to nonlinear model of the building developed using generally accepted engineering practice may lead to either significant over-estimation or under-estimation of the targetroof displacement when compared with the peak roof displacement observed during a selected earthquake. The error ranged between $50 \%$ underestimation to $40 \%$ overestimation.

It is useful to note that poor estimates of target displacement for a few of the buildings from the various pushover analysis procedures may be due to severe nearfault effects as noted previously by Akkar and Metin [5]. Additional errors may occur due to loss of accuracy in recorded roof displacement resulting from data processing techniques described previously. Furthermore, nonlinear static procedures are designed to provide "accurate" estimate 


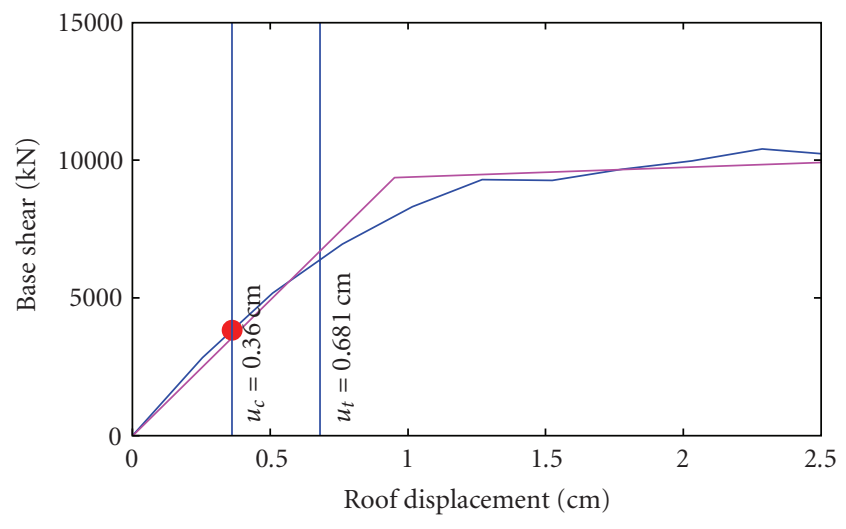

(a) FEMA-356 CM

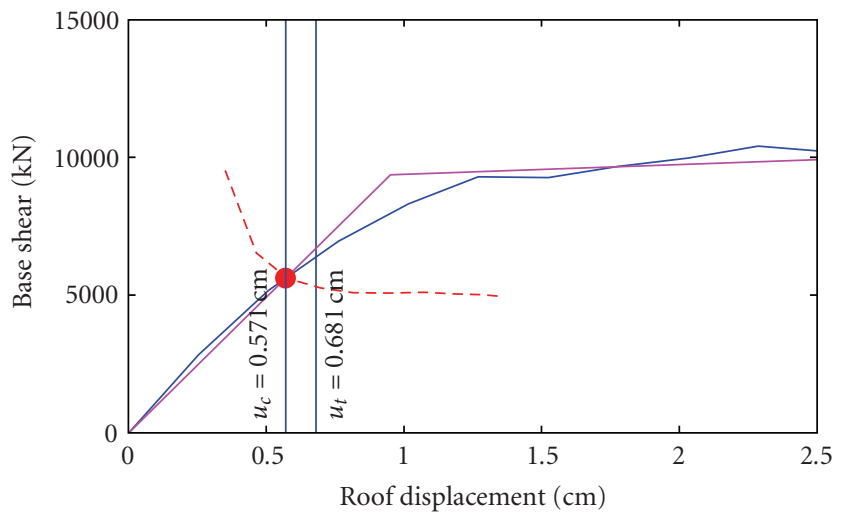

(c) ATC-40 CSM

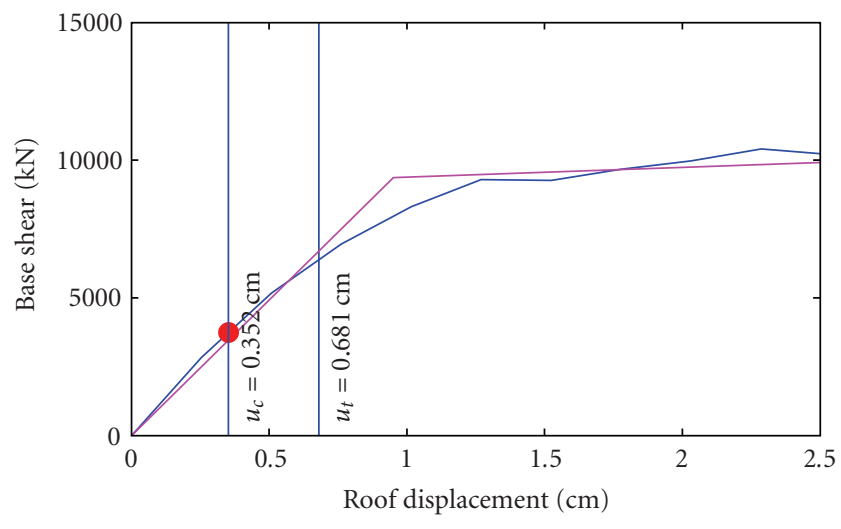

(b) ASCE-41 CM

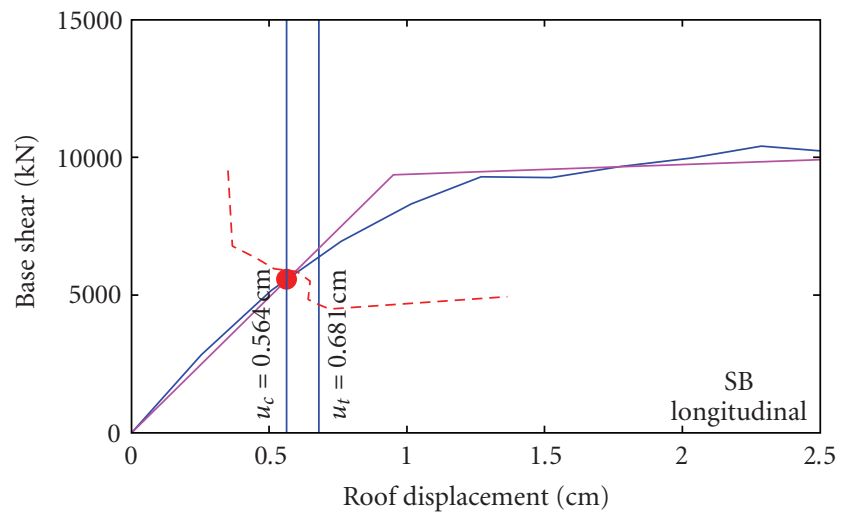

(d) FEMA-440 CSM

FIgure 13: Computation of the roof displacement from the FEMA-356 CM, ASCE-41 CM, ATC-40 CSM, and FEMA-440 CSM in the longitudinal direction of the Santa Barbara Office Building.

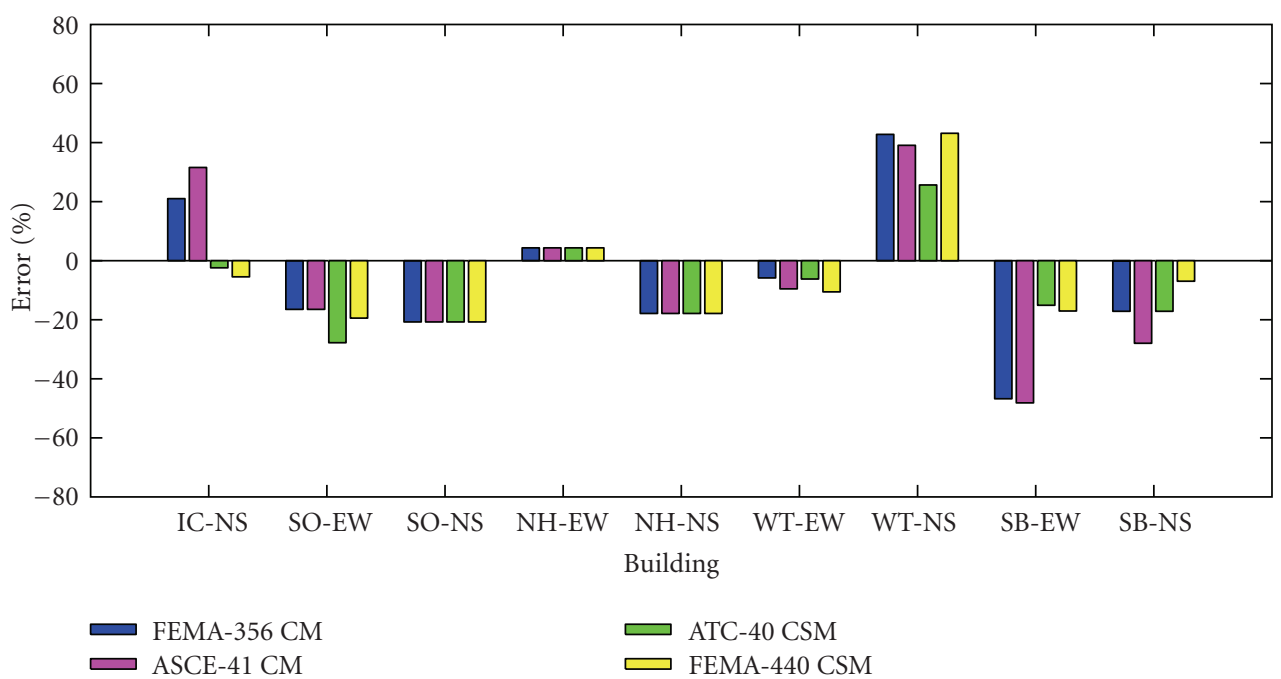

FIGURE 14: Percent error in peak roof displacements from the FEMA-356 CM, ASCE-41 CM, ATC-40 CSM, and FEMA-440 CSM.

of the median response. Therefore, it is not surprising that large errors are noted when these procedures are applied to predict target displacement of buildings during individual ground motions. The large errors noted here are also because of a combination of errors due to nonlinear static procedures and inaccuracies associated with nonlinear modeling.

The data presented in this investigation also provides a comparative prediction capability of various nonlinear static procedures. Although limited in size, this data indicates 
that (1) the ASCE-41 CM, which is based on recent improvements to the FEMA-356 CM suggested in FEMA440 document, does not necessarily provide better prediction of roof displacement, (2) the improved FEMA-440 CSM also may not provide better prediction of peak roof displacements compared to the ATC-40 CSM, and (3) there is no conclusive evidence that the CM procedures (FEMA-356 or ASCE-41) provide better predictions of the peak roof displacement compared to the CSM procedure (ATC-40 or FEMA-440) or vice-versa.

\section{Acknowldegments}

This investigation is supported by the California Department of Conservation, California Geological Survey, Strong Motion Instrumentation Program (SMIP), Contract no. 1005-832. This support is gratefully acknowledged. The authors are grateful to Drs. Anthony Shakal, Moh Huang, and Erol Kalkan of SMIP for providing the recorded motions and structural plans of the selected buildings. The authors also acknowledge the contributions to this research investigation by Matthew Hazen and Joey Givens, undergraduate students at Cal Poly, San Luis Obispo and by Dr. Dae-Han Jun, Visiting Professor from Dongseo University, Korea.

\section{References}

[1] FEMA 356, Prestandard and Commentary for the Seismic Rehabilitation of Buildings, FEMA Publication no. 356, The American Society of Civil Engineers for the Federal Emergency Management Agency, Washington, DC, USA, 2000.

[2] ATC-40, "Seismic evaluation and retrofit of concrete buildings, volumes 1 and 2," Tech. Rep. ATC-40, Applied Technology Council, Redwood City, Calif, USA, 1996.

[3] FEMA-440, Improvement of Nonlinear Static Seismic Analysis Procedures, Applied Technology Council for Department of Homeland Security, Federal Emergency Management Agency, Washington, DC, USA, 2005.

[4] E. Miranda and J. Ruiz-García, "Evaluation of approximate methods to estimate maximum inelastic displacement demands," Earthquake Engineering and Structural Dynamics, vol. 31, no. 3, pp. 539-560, 2002.

[5] S. Akkar and A. Metin, "Assessment of improved nonlinear static procedures in FEMA-440," Journal of Structural Engineering, vol. 133, no. 9, pp. 1237-1246, 2007.

[6] ASCE/SEI-41, "Seismic rehabilitation of existing building," ASCE Standard no. ASCE/SEI 41-06, American Society of Civil Engineers, Reston, Va, USA, 2007.

[7] A. C. Guyader and W. D. Iwan, "Determining equivalent linear parameters for use in a capacity spectrum method of analysis," Journal of Structural Engineering, vol. 132, no. 1, pp. 59-67, 2006.

[8] A. F. Shakal, M. J. Huang, and V. Graizer, "Strong-motion data processing," in International Handbook of Earthquake Engineering Seismology, Part B, W. H. K. Lee, H. Kanamori, P. C. Jennings, and C. Kisslinger, Eds., pp. 967-981, Academic Press, Amsterdam, The Netherlands, 2003.

[9] A. K. Chopra, Dynamics of Structures: Theory and Applications to Earthquake Engineering, Prentice-Hall, Upper Saddle River, NJ, USA, 3rd edition, 2007.
[10] F. McKenna and G. Fenves, The Opensees Command Language Manual: 1.2, Pacific Earthquake Engineering Center, University of California, Berkeley, Calif, USA, 2001, http://opensees.berkeley.edu/.

[11] J. B. Mander, M. J. N. Priestley, and R. Park, "Theoretical stress-strain model for confined concrete," Journal of Structural Engineering, vol. 114, no. 8, pp. 1804-1826, 1988.

[12] R. K. Goel and A. K. Chopra, "Evaluation of modal and FEMA pushover analyses: SAC buildings," Earthquake Spectra, vol. 20, no. 1, pp. 225-254, 2004.

[13] K. J. Elwood, A. B. Matamoros, J. W. Wallace et al., "Update to ASCE/SEI 41 concrete provisions," Earthquake Spectra, vol. 23, no. 3, pp. 493-523, 2007.

[14] R. K. Goel and C. Chadwell, "Evaluation of current nonlinear static procedures for concrete buildings using recorded strongmotion data," Data Utilization Report, California Strong Motion Instrumentation Program, CDMG, Sacramento, Calif, USA, 2007, http://digitalcommons.calpoly.edu/cenv_fac/172/.

[15] ATC-9, "An evaluation of the imperial county services building: earthquake response and associated damage," Tech. Rep. ATC-9, Applied Technology Council, Palo Alto, Calif, USA, 1984. 

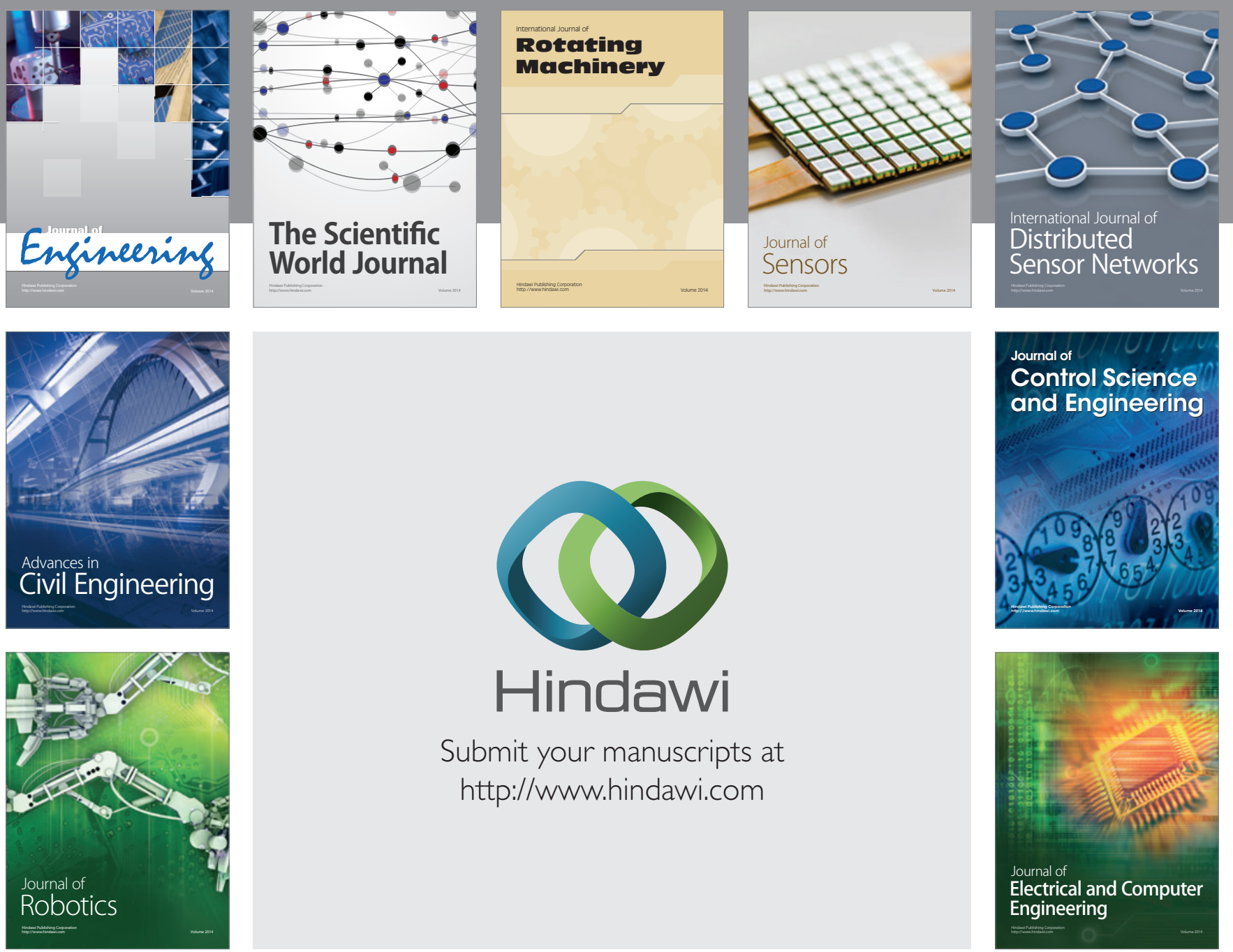

Submit your manuscripts at

http://www.hindawi.com
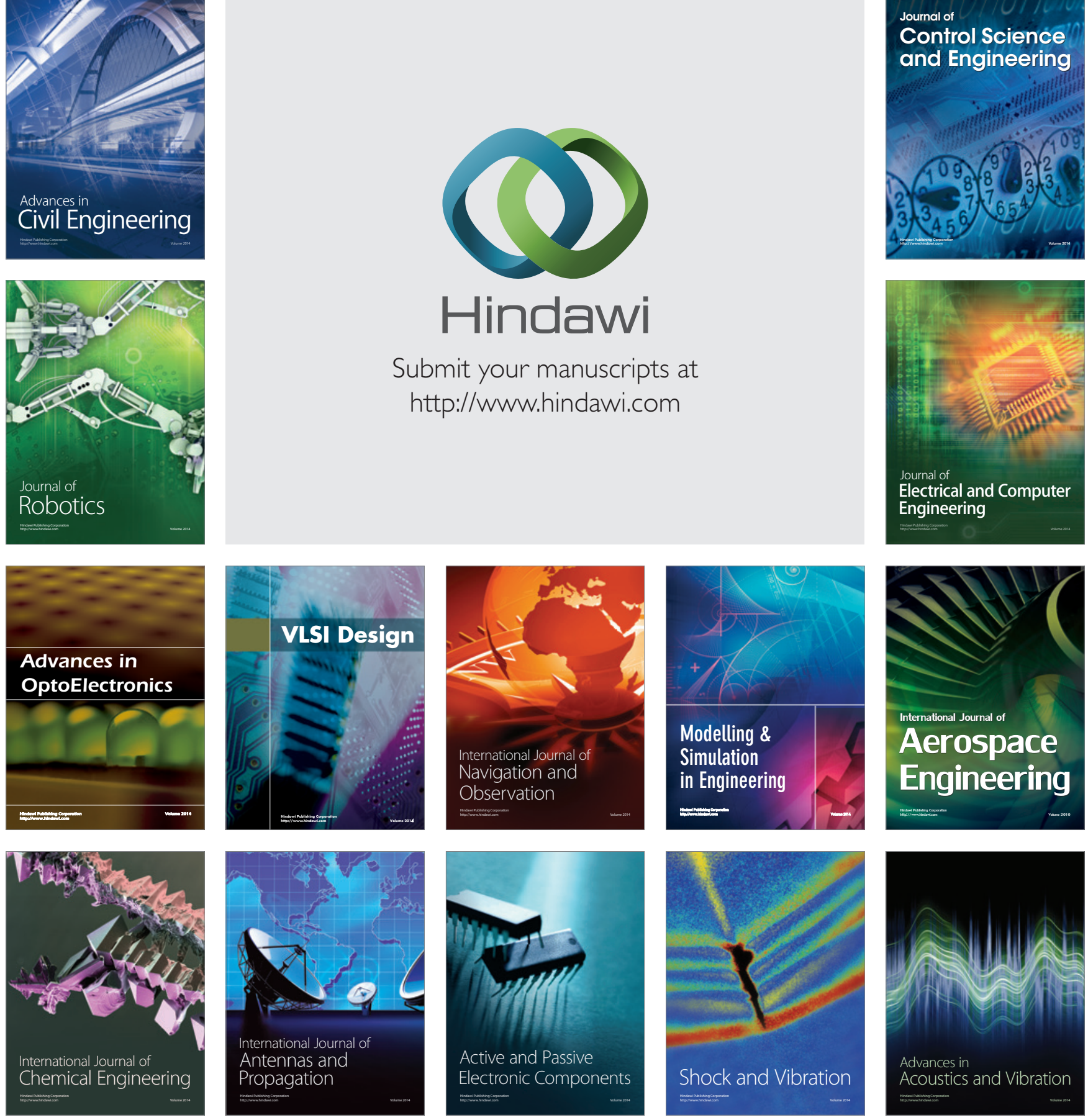